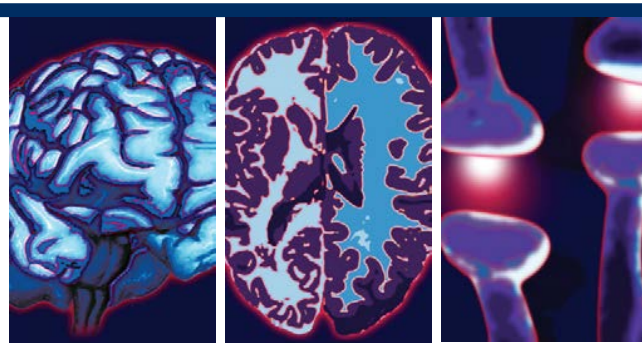

\title{
Effects and Therapeutic Use of TMS in Psychiatric Disorders: An Evidence-Based Review
}

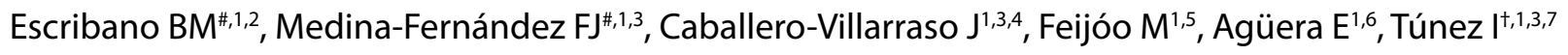

\begin{abstract}
Objective

Recently we found that chronic immobilization stress (CIS) induced low levels of glutamate (Glu) and glutamine (Gln) and hypoactive glutamatergic signaling in the mouse prefrontal cortex (PFC), which was closely related with Glu-Gln cycle. Moreover, Gln-supplemented diet ameliorated CISinduced deleterious changes. In the present study, therefore, we investigated the effects of CIS and Gln supplementation on Glu-Gln cycle-related proteins to understand underlying mechanisms.
\end{abstract}

\section{Methods}

Using CIS-induced depression mouse model, we confirmed depressive behaviors caused by $\mathrm{ClS}$ and antidepressant property of Gln-supplementation with behavioral test and blood corticosterone assay. We examined expression of eleven proteins involving Glu-Gln cycle in the PFC.

\section{Results}

CIS decreased glutamate transporter 1 (GLT1), sodium-coupled neutral amino acid transporter (SNAT) 3, SNAT5, and mature SNAT2, suggesting excitotoxicity in synaptic cleft and shortage of Glu and Gln in astrocytes and neurons. Gln-supplementation did not affect non-stressed group, but significantly increased SNAT1 and SNAT3, which are the major Gln transporter in neurons and astrocytes respectively, as well as the mature SNAT2, implicating increasing transportation of Gln into neurons.

\section{Conclusion}

As a result, we confirmed that CIS disturbed Glu-Gln cycle toward shortage of Glu and Gln levels in astrocytes and neurons, but Gln supplementation changed Glu-Gln cycle toward facilitating translocation of Gln into neurons for glutamatergic signaling. Moreover, these results also supported the antidepressant property of Gln.

\section{Keywords}

Depression, Chronic stress, Glutamine, Glutamate-glutamine cycle, Glutamate transporter, Glutamine transporter, Prefrontal cortex

\footnotetext{
'Maimonides Institute for Research in Biomedicine of Cordoba, (IMIBC), Cordoba, Spain

${ }^{2}$ Department of Cell Biology, Physiology and Immunology, Faculty of Veterinary Medicine, University of Cordoba, Spain

32Department of Biochemistry and Molecular Biology, Faculty of Medicine and Nursing, University of Cordoba, Spain

${ }^{4}$ Clinical Analysis Service, Reina Sofia University Hospital, Cordoba, Spain

${ }^{5}$ Department of Medical-Surgery Specialties, Faculty of Medicine and Nursing, University of Cordoba, Spain

${ }^{6}$ Neurology Service, Reina Sofia University Hospital, Cordoba, Spain

${ }^{7}$ Red Tematica de Investigacion Cooperativa en Envejecimiento y Fragilidad (RETICEF).

"These Authors contributed equally

${ }^{\dagger}$ Author for correspondences: Dr. Isaac Túnez. Dept. Biochemistry and Molecular Biology, Faculty of Medicine and Nursing, Av, Menendez Pidal s/n, Cordoba 14004, Cordoba, Spain, email: fm2tufii@uco.es
} 


\section{Introduction}

Transcranial Magnetic Stimulation (TMS) has been developed on the basis of a possible modulation of brain performance according to its electric environment. The physical process involved in TMS is simple and consists of the transformation of an electromagnetic field created by two coils connected to a generator into electrical energy when it passes through the skull and nervous tissue. This process, being safe [1], produces a transfer of ions across the cell membrane, finally leading to its depolarization or hyperpolarization. This results in stimulation or inhibition of the neuronal groups involved that are translated into clinical effects [2].

Psychiatric disorders have a histopathological basis that, in the vast majority of them, is not well characterized so that the symptoms are commonly defined as "pathophysiological disorder". In this regard, psychiatric diseases seem to share alterations in the flow of brain neurotransmitters, especially serotonin, norepinephrine and dopamine; as well as other alterations in neurotropism, neuronal plasticity and biochemical processes related to cell dysfunction. Due to the ability demonstrated by TMS to act on all those processes [3], this fact might be at the basis of the therapeutic effects of TMS in psychiatric conditions such as schizophrenia, major depression and other mood disorders [4].

Nevertheless, to date, although high-frequency repetitive transcranial magnetic stimulation (HF-rTMS) and low-frequency repetitive transcranial magnetic stimulation (LF-rTMS) remain as classic protocols; many other paradigms of TMS have been defined. Their different effects are closely related to the target of the stimulation, frequency used, and the number of stimuli or sessions, among others. Thus, with a constantly increasing number of publications on this area, it may be difficult to differentiate which protocols and in which clinical settings are really useful. According to this background, the aim of this review is to present the proven clinical therapeutic effects of TMS in psychiatric disorders, their possible underlying mechanisms and the determinants that may vary their outcomes, all according to the maximum level of evidence found to date.

To achieve this objective, an extensive review was conducted in PubMed.gov using "transcranial magnetic stimulation" as a search term. No limitations were imposed. All references retrieved until October 2018 was carefully reviewed in looking for papers on therapeutic effects of TMS in psychiatric disorders. The inclusion criterion was the communication of a therapeutic effect. Studies regarding TMS as a non-therapeutic tool and those treating non-psychiatric conditions were excluded. Studies reporting experimental models were also considered. Initially, all types of publications were selected and, in a second step, only those with a maximum level of evidence found in each case were selected and included in the present manuscript (Figure 1). Evidence was established according to the document "Levels of Evidence 1" of the Oxford Centre for Evidence-Based Medicine (OCEBM), Levels of Evidence Working Group (March 2009).

In summary, this paper seeks to provide an evidence-based point of view of the therapeutic effects induced by current TMS-protocols, also briefly showing their possible biochemical pathways and clinical outcome determinants.

\section{Schizophrenia}

Schizophrenia is a common, serious and chronic psychiatric disorder with a globally lifetime prevalence of $0.5 \%$ to $1 \%$ [5]. The core alterations of this disorder are in relation to changes in the perception of reality. Its symptomatology has been classically divided into: positive (mainly hallucinations and delusions) and negative symptoms (emotional poverty, anhedonia, alogia and total apathy). The predominance of positive or negative symptoms allows the classification of this pathology into several clinical presentations that have their peculiarities in terms of evolution and treatment.

Pathophysiology of schizophrenia and determinants underlying the therapeutic effect of TMS

In recent years, the pathophysiology of schizophrenia has been extensively studied in order to find new therapies for this tragic disease. Toward this end, animal models play a key role [5]. Several studies have permitted one to demonstrate that the brain of patients with schizophrenia undergoes various pathophysiological alterations, which affect the flow of neurotransmitters such as dopamine, GABA, and glutamate; as well as the expression of genes and receptors related to them [68]. Moreover, these patients have also shown alterations in neurotrophic and neuroplastic processes $[8,9]$, immune system and the secretion 


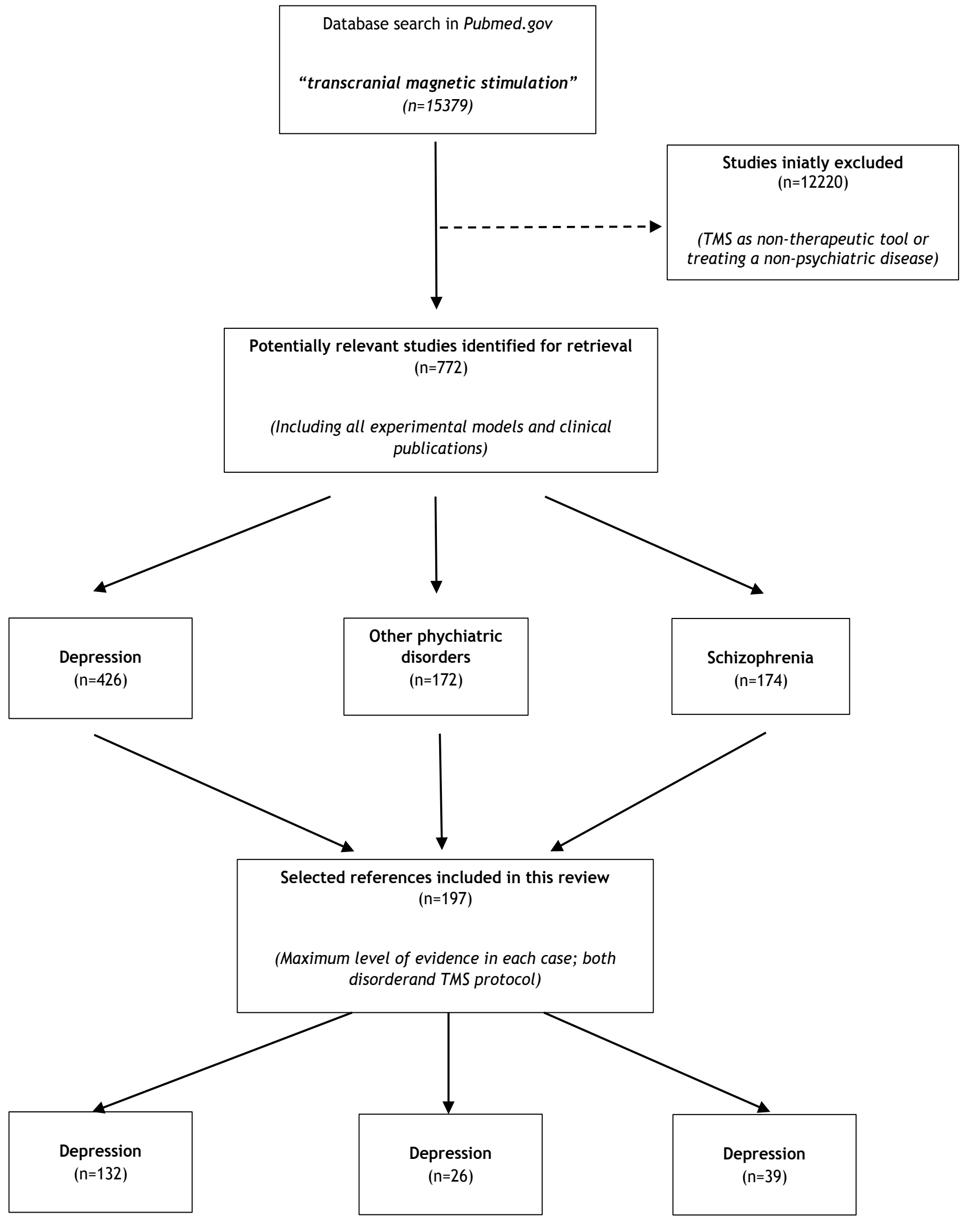

Figure 1: Flow diagram showing yield of search and selection strategy. 
of pro-inflammatory cytokines [10,11], as well as oxidative balance $[12,13]$, processes that can be modulated and counteracted by therapeutic TMS [3].

In this same line, according to some studies, the positive effects on symptomatology may be connected to both a reduction in hyperactivity, and, therefore, metabolism objectified in language regions involved in the emergence of auditory verbal hallucinations (AVH) [14], and a decreased cerebral blood flow in the primary auditory cortex [15], a finding that could be used to identify responders to therapy with TMS [16].

On the other hand, it has been suggested that the normalization of alpha and gamma oscillations related to the cognitive disorders in these patients may hold the key to the therapeutic outcomes of TMS in schizophrenia [17]. In this sense, it has been proven that Alpha and delta electroencephalography (EEG) normalization after treatment with Alpha-Delta-EEG-guided TMS (alpha TMS) over frontal and parietal areas may directly subserve the processes underlying clinical improvements in schizophrenia $[18,19]$. Similarly, rTMS therapy over the DLPFC may normalize excessive gamma oscillations and, ultimately, cognitive performance in schizophrenic patients [20].

On these bases, TMS might offer a therapeutic alternative to classic antipsychotic drugs, especially in those neuroleptic-resistant cases.

Effectiveness and medical evidence of classic rTMS-protocols in clinical settings

It has been about twenty years since the first references pointing to a possible therapeutic effect of TMS in schizophrenia were published $[21,22]$. Since then, numerous randomized clinical trials (RCTs) have been carried out to assess the effect of TMS on positive and negative symptoms. These results allowed the elaboration of several systematic reviews and meta-analyses that corroborate the potential use of this therapy, especially in those cases refractory to conventional treatment [23].

In this regard, a meta-analysis supporting a beneficial effect of repetitive transcranial magnetic stimulation (rTMS) on the AVH has been published by Slotema et al. [24]. This metaanalysis that included seventeen RCTs using LF-rTMS, evaluated AVH severity or psychosis severity as a primary goal. It concluded that the mean weighted effect size of rTMS when directed toward the left temporo-parietal cortex was 0.44 (95\% CI, $0.19-0.68)$. However, this effect was no longer significant at one-month follow-up in any of the RCTs. According to some authors, this effect might be prolonged by up to six months using HF-rTMS $(20 \mathrm{~Hz})$ and functional magnetic resonance imaging (fMRI) to address the stimulation [25].

The results of the meta-analysis by Slotema et al. [24] are consistent in terms of therapeutic effectiveness on AVH with other similar works previously published [26,27]. Among them, it should be noted that, in 2007, Aleman et al. carried out a meta-analysis that included ten RCTs in which patients underwent LF-rTMS (1 $\mathrm{Hz}$ ) to the left temporoparietal cortex [26]. After treatment calculation, the hallucination ratings gain obtained a significant mean weighted effect size for rTMS versus sham across the ten studies, involving 212 patients, $\mathrm{d}=0.76$ (95\% CI, 0.36 1.17). This parameter increased to $d=0.88$ when only nine studies using continuous stimulation were included. In addition, the heterogeneity of the analysis disappeared, thus proving the efficiency of LF-rTMS (1 Hz) on AVH [26]. This work found no beneficial effect on other positive symptoms as it was also concluded by another meta-analysis that included all prospective studies of the therapeutic application of LF-rTMS over the left temporoparietal cortex in refractory schizophrenia [28].

A study including twenty-one articles concerning 303 patients evaluated the magnitude of the placebo effect observed in controlled studies of rTMS treatment of AVH [29]). The mean weighted effect size of the placebo effect across these 21 studies was 0.29 ( $\mathrm{P}<0.001)$, but when the 21 articles were divided into parallel and crossover studies, only the placebo had a significant effect size in the 13 parallel studies $(\mathrm{g}=0.44, \mathrm{P}<10(-4))$, but not in the 8 crossover ones ( $\mathrm{g}=0.06, \mathrm{P}=0.52)$.

In this latter study, Freitas et al. [28] also performed an analysis with pooled data from eight clinical trials that evaluated the effect of HFrTMS $(10 \mathrm{~Hz}-20 \mathrm{~Hz})$ over the left dorsolateral prefrontal cortex (DLPFC) in the treatment of negative symptoms. In this regard, just a small beneficial effect was noted when including all studies. However, this effect disappeared when a potential placebo effect was considered, so that the usefulness and/or clinical relevance of HF-rTMS therapy in negative symptoms of patients with schizophrenia is doubtful and may 
be conditioned to the psychopathology severity and differences in results, measurements or TMS parameters [28].

A similarly slight effect on negative symptoms was found by another meta-analysis published a year later [30]. This study included nine RCTs (213 patients) that used HF-rTMS to the left DLPFC for the treatment of negative symptoms, and concluded that the overall mean weighted effect size for rTMS versus sham was statistically significant, $d=0.43$ (95\% CI, $0.05-0.80)$ [30]. It should be noted that this mild effect improved when analyzed by subgroups. Therefore, this result rose when only studies with HF-rTMS $(10 \mathrm{~Hz})$ or a duration of treatment $\geq 3$ weeks were included, $\mathrm{d}=0.63(95 \% \mathrm{CI}, 0.11-1.15)$ and $\mathrm{d}=0.58$ (95\% CI, $0.19-0.97)$, respectively; and decreased when only considering studies of patients who were in a stable drug regime before and during the trial, $\mathrm{d}=0.34(95 \% \mathrm{CI}, 0.01$ 0.67) [30].

A recent meta-analysis that includes studies up to December, 2017 [31] on rTMS treatment in schizophrenia, established that, for rTMS treatment, the mean weighted effect size compared to sham stimulation was 0.64 (0.32-0.96; $\mathrm{k}=22$, total $\mathrm{N}=827$ ) showing that noninvasive neurostimulation can improve negative symptoms in patients with schizophrenia. Moreover, this study suggested that protocols with high frequency stimulation containing more than 7500 stimuli per week at an intensity of $>100 \%$ motor threshold, may be more effective than other protocols especially in younger patients with a shorter duration of illness.

Another meta-analysis [32] revealed that at a $10 \mathrm{~Hz}$ setting at least 3 consecutive weeks of treatment, treatment site DLPFC and a $110 \%$ motor threshold were found to be the best rTMS parameters for the treatment of negative symptoms, although the application of active 10-Hz rTMS to the left dorsolateral prefrontal cortex was well tolerated, but it was not superior compared with sham rTMS in improving negative symptoms in another recent study [33] on 175 patients with a high-degree illness severity.

Dougall et al. [34], however, conclude that there is insufficient evidence to support or refute the use of TMS to treat schizophrenia symptoms, and none to suggest any added benefits with TMS used as an adjunctive therapy to antipsychotic medication. The study included 41 studies with 1473 participants.

\section{Other paradigms and preliminary studies}

Up to this moment, the vast majority of studies with rTMS for this pathology have included in their protocol either LF-rTMS over temporoparietal cortex to treat AVH or HFrTMS to the left DLPFC for negative symptoms. In the search for novel target sites or protocols to improve outcomes, a preliminary study using HF-rTMS $(20 \mathrm{~Hz})$ guided by anatomical and fMRI has reported a significant reduction in global severity and frequency of AVH between baseline and day 12 post-treatment [25]. Moreover, according to its authors, some of these effects continued for up to six months [25].

On the other hand, a case-report revealed that HF-rTMS (5 - $7 \mathrm{~Hz}$ ) over the cerebellar vermal may result in the worsening of AVH [35], contrary to the results of a series of eight cases in which the application of intermittent theta burst stimulation (iTBS) (short trains of $50 \mathrm{~Hz}$ with a rate of $5 \mathrm{~Hz}$ (theta rhythm)) over the same area that to be safe and well-tolerated, while offering a positive impact on mood and cognition [36].

It should be noted that the application of theta burst stimulation (TBS) is faster and appears to induce more lasting effects than those achieved by conventional rTMS. This paradigm is mainly inhibitory when applied continuously (cTBS) and excitatory when done so intermittently [37]. Regarding TBS and schizophrenia, three casereports revealed improvement of untreatable AVH after the application of cTBS over left temporoparietal cortex $[38,39]$ and the same area bilaterally [40]. These findings set the basis for the development of a RCT that compared treatment with classical LF-rTMS $(1 \mathrm{~Hz})$ to cTBS over the left temporoparietal cortex, concluding that cTBS is safe, faster but does not have clinical advantages compared with the conventionally used 1-Hz TMS protocol in AVH [41].

Similarly, in contrast to the normal use of the left DLPFC to improve negative schizophrenia symptoms by means of HF-rTMS, Dablac-deLange et al., [42], used bilateral DLPFC in a study employing $10 \mathrm{~Hz}$ for 3 weeks, concluding that bilateral $10 \mathrm{~Hz}$ prefrontal rTMS reduced negative symptoms for up to 3 months after its application compared to the sham group.

To summarize, taking into account the evidence found, it could be concluded that LF-rTMS over left temporoparietal cortex may be an effective treatment for AVH but not for other positive symptoms. Furthermore, the duration of the effects of rTMS over AVH is short. This 
inconvenience, combined with a small treatment effect, may call into question its utility as a useful treatment for patients troubled with persistent symptoms. In terms of negative symptoms, in spite of the promising results of some studies, the potential of HF-rTMS for the treatment of negative symptoms is currently relatively unclear. Thus, further RCTs are needed to clarify the role of TMS in the treatment of schizophrenia.

\section{Depression}

The therapeutic effects demonstrated by TMS in depression have become the paradigm of the effectiveness of this therapy.

\section{Pathophysiology of depression and mech- anisms underlying the therapeutic effect of TMS}

Depression is one of the most prevalent mood disorders in existence. It is estimated that in the U.S. around one out of every six subjects will suffer from any form of clinical depression throughout their lives, often closely related to other neurodegenerative processes such as Alzheimer's disease (AD), Parkinson's disease (PD), or Huntington's disease (HD) among others. The core symptom of this disorder is to be in a low mood, although depression is always accompanied by other symptoms such as irritability, anhedonia, and disturbances in sleep, appetite, and cognitive functions. The diagnosis of a major depressive disorder (MDD), as well as other clinical forms of depression, is based on several diagnosis criteria perfectly defined in the Diagnostic and Statistical Manual of Mental Disorders (fourth edition; DSM - IV). However, its pathophysiological mechanisms have not yet been fully elucidated $[43,44]$.

In this direction, experimental models have linked depression to oxidative stress and cell damage [45]. Supporting this hypothesis, treatment with proven antioxidant- effect substances such as $17 \beta$-estradiol, nicotine and melatonin have been demonstrated to reverse the oxidative changes and behavioral alterations induced by the models [45-47]. In addition, treatment with extremely low-electromagnetic field (EL-EMF) $(60 \mathrm{~Hz}, 0.7$ $\mathrm{mT}$ ), a type of electromagnetic therapy similar to TMS, achieved similar effects to those induced by antioxidant substances [48] and even to those found in similar experimental models after the application of electroconvulsive therapy (ECT) $[49,50]$.
From another point of view, a great deal of scientific evidence supports the role of alterations in brain-derived neurotrophic factor (BDNF)-mediated neuroplasticity, as well as the participation of proinflammatory cytokines as adjuvants in the pathogenesis of this complex disorder [43,44]. According to some authors, oxidative stress markers and BDNF might even become future depression biomarkers [51]. In this respect, the application of HF-rTMS $(20 \mathrm{~Hz})$ produces changes in the expression of BDNF and cholecystokinin in rat brain, data that are consistent with those found after administration of antidepressant drugs (mianserin, desimipramin or sertraline) and ECT [52], pointing to this route as being one of the bases for the therapeutic effect of TMS in mood disorders such as depression [53]. Similarly, after successful antidepressive treatment with HF-rTMS $(15 \mathrm{~Hz})$ over left prefrontal cortex, myo-Inositol, an alcohol involved in functions such as nerve guidance, cell membrane potential maintenance or serotonin activity modulation, increased significantly in left prefrontal cortex emphasising the importance of metabolic alterations in major depression [54]. Nevertheless, it is beyond question that the pathophysiology of depressive disorders is extremely complex and not exclusively a problem of oxidative damage and cell dysfunction.

Thus, depression appears to be associated with pathophysiological and structural brain abnormalities such as dysregulation of hypothalamo-pituitary-adrenal and hypothalamo-pituitary-thyroid axes, reduced hippocampal volumes and prefrontal cortex activity [44]. Genetic vulnerability and stress have also been proposed as being pathogenic elements in depression [44].

In this line, depressive patients who respond to TMS therapy (HF-rTMS $10 \mathrm{~Hz}$ over left prefrontal cortex) showed an elevation of serum levels of the thyroid-stimulating hormone (TSH) [55]. Similarly, a negative correlation between pre-treatment TSH levels and decrease (\%) in the Hamilton Rating Scale for Depression (HAM-D) score has been reported using LFrTMS (1 Hz) over the right DLPFC [56].

There is also evidence that the hypothalamicpituitary-adrenal axis is modified by application of HF-rTMS $(10 \mathrm{~Hz})$ to the left DLPFC, significantly decreasing salivary cortisol concentrations immediately and 30 minutes after rTMS, regardless of its effect on mood [57]. 
Similar changes in this axis have been observed in both healthy subjects [58] and animals [59], and they could explain why rTMS normalizes the dexamethasone suppression test, a remission feature in depressive patients under treatment $[60,61]$.

Finally, a well-defined disorder of neurotransmitters (mainly serotonin and norepinephrine, but also others) occurs in depression, the latter being the basis of current pharmacological treatment. Nowadays, the most commonly used drugs are the selective serotonin re-uptake inhibitors (SSRIs), although classic tricyclic antidepressants or serotoninnorepinephrine reuptake inhibitors (SNRIs) are presented as an alternative or even first line treatment in some cases. Nevertheless, despite the good outcomes of antidepressant drugs, there are a considerable number of patients who will not respond to therapy with these medicaments. For this subgroup, TMS treatment, due to its capacity to modulate some pathophysiological processes involved in the neurobiology of depression has been proven effective as a therapeutic alternative [62].

\section{Medical evidence and clinical effectiveness} of classic rTMS-protocols on depression

In October 2008, the U.S. FDA approved the first TMS devices (NeuroStar TMS TherapyC System, Neuronetics, Inc., Malvern, PA, US) which, to date, are only authorized for the treatment of patients with MDD that failed to respond to one appropriate pharmacological treatment. This landmark was possible after more than one decade of research. The first preliminary studies and series of cases published in this respect date from the mid-1990s [6365]. In subsequent years, and up to the FDA's approval, approximately a hundred clinical trials have been carried out, concluding from the vast majority of them, that TMS causes a therapeutic effect on patients with MDD.

Probably due to the fact of being an emerging technique whose stimulation parameters were not standardized, as well as the initial absence of RCTs, the first meta-analyses that assessed the efficacy of TMS therapy in MDD resulted in offering a very low level of evidence or were of a doubtful clinical significance [66-69]. However, to prove the hypothesis that the experience accumulated over the years in the use of TMS, as well as a better study design, had improved the outcomes of this therapy in MDD, in 2007, Gross et al. [70] compared a meta-analysis of five RCTs (274 patients) published just twelve months prior to their paper with the meta-analysis of Martin et al. [67] (thirteen RCTs, 324 patients) that represented "the earlier studies". Their findings demonstrated that recent RCTs (five) using HF-rTMS showed greater antidepressant effects when compared with the earlier studies. The pooled effect size (standardized mean difference between pretreatment vs. post-treatment) from the random effects model was -0.76 (95\% CI, $-1.01-0.51)$ versus -0.35 (95\% CI, -0.66 $-0.04)$, respectively [70]. Later studies, including one meta-analysis (29 RCTs, 1371 subjects with MDD) [71], corroborate the hypothesis of Gross et al. [70] pointing to HF-rTMS applied to the left DLPFC as a safe and effective therapeutic tool in both acute and maintenance treatment of patients with MDD [72-75]. Furthermore, according to some authors, HF-rTMS therapy to the left DLPFC may be at least as effective as a subset of commercially available antidepressant drug agents [76] and undoubtedly, accelerates and enhances the clinical response to antidepressants $[77,78]$.

Regardless of the effect on mood demonstrated by this therapy, some authors have suggested that TMS, mainly HF-rTMS $(20 \mathrm{~Hz})$ over the left DLPFC, may have an impact on psychomotor symptoms accompanying those patients with MDD. However, the scant literature existing in this regard is contradictory, not allowing one to confirm or rule out this hypothesis until new RCTs are carried out focusing on this issue $[79,80]$. Regarding other symptoms, treatment of depressive patients with rTMS, both HFrTMS and LF-rTMS, not only does not worsen cognitive function [81] but, according to some works, results in a beneficial effect in working memory-executive function, objective memory or fine motor speed domains [82-86].

Regarding remission and relapse rates, the most recent long-term follow-up studies report that over $50 \%$ of the patients treated with HF-rTMS $(10 \mathrm{~Hz})$ over the left DLPFC remain in remission for three months post-treatment $[87,88]$. A similar trial carried out with adolescent patients is much more optimistic since it concludes that eight out of nine treated patients showed no evidence of deterioration in symptoms of depression or cognitive functioning at a 3-year follow-up [89], although the level of evidence of this trial is low. In this line, in order to maintain long-term remissions and avoid early relapses, clustered-maintenance rTMS which involves 
monthly maintenance sessions of five HF-rTMS treatments over a two day period, may have the potential to substantially delay the occurrence of relapse following a successful course of rTMS treatment [90]. Two years earlier, a study using similar methodology had already pointed to this possibility [88]. Similarly, in patients with partial remission after drug treatment, ten sessions of HF-rTMS $(10 \mathrm{~Hz})$ over the left DLPFC may lead to achieve rates of complete remission (HAM-D < 8) of up to $78 \%$ at 12 months [91]. In this respect, a RCT is currently running to evaluate the efficacy of HF-rTMS $(10 \mathrm{~Hz})$ over the left DLPFC in the prevention of relapse of depression [92].

Despite the above mentioned studies, rTMS remains as a second-line therapy in MDD. Data from meta-analyses report relatively low response and remission rates $(25-29.3 \%$ and $17-18.6 \%$, respectively) [71-93], with a short duration of therapeutic effects in many cases (weeks to months), and a warning about the relative lack of systematic follow-up studies. For these reasons, further RTCs are needed before HF-rTMS can be considered as a first-line monotherapy treatment for MDD [93].

To conclude this section, it should be highlighted that TMS therapy may also be a valid method to treat the depressive disorder associated with other neurodegenerative and psychiatric conditions. Such is the case of Parkinson disease (PD) in which, in addition to motor and cognitive improvements, HFrTMS $(5 \mathrm{~Hz})$ over the left DLPFC has exerted an antidepressant effect [94]. According to some authors, this intervention might be as effective as fluoxetine, a SSRI [95]. Similarly, in postpartum depression, the application of HF-rTMS (5 $\mathrm{Hz}$ or $10 \mathrm{~Hz}$ ) may become a safe and effective alternative to pharmacological treatment, besides producing marginal gains in social and cognitive function [96,97]. Equally, LF-rTMS $(1 \mathrm{~Hz})$ over right DLPFC seems to be effective in the treatment of panic disorder with comorbid major depression [98], and HF-rTMS $(10 \mathrm{~Hz})$ over the right DLPFC may improve depression secondary to obsessive-compulsive disorder [99]. Moreover, in a RCT of twenty-two women with MDD in the second or third trimester of pregnancy that received 20 sessions of TMS to the right dorsolateral prefrontal cortex at $1 \mathrm{~Hz}$ as a single train of 900 pulses per session at $100 \%$ motor threshold, demonstrated that TMS was effective in reducing depressive symptoms in this sample of pregnant women. However, there is a possibility that TMS could be associated with late preterm birth, although a larger sample size would be needed to detect it [100]. Finally, the effect of rTMS therapy on mood has also been observed in patients with fibromyalgia [101].

\section{Predictive factors of responders to TMS treatment}

The possibility of foreseeing which patients will respond to a specific treatment is a basic endpoint in many medical trials. In addition to the potential therapeutic benefit for a certain subgroups of patients, it improves the costeffectiveness ratio of the therapy. In the work concerning us, several studies have been carried out with interesting results to answer this question (Table 1).

In 2006, Fregni et al. pooled data from six separate clinical trials (195 patients) concluding that age and treatment refractoriness were significant negative predictors of depression improvement [102]. Later, other studies have corroborated the hypothesis that young patients show better antidepressant response to LF-rTMS $(1 \mathrm{~Hz})$ over the right DLPFC than older ones [103]. In the same line, Brakemeier et al., in a study with 70 depressive patients, after analyzing various biographical, clinical, and psychopathological parameters, concluded that a high level of sleep disturbance, a low score of treatment resistance and a short duration of depressive episode were significant positive predictors for treatment response to HF-rTMS $(20 \mathrm{~Hz})$ over the left DLPFC [104]. A year later, this same research group, using these data combined with Fregni's [102], carried out a joint analysis of the two studies, whose unique relevant conclusion was that a high level of therapy resistance is associated with poor outcome, suggesting that future predictor studies should focus on large, homogeneous samples of TMS multicentre trials and include neurobiological variables [105]. Finally, a study in 117 patients, with mood or anxiety disorders, have demonstrated that 10 sessions of HF-rTMS $(10 \mathrm{~Hz})$ over the left DLPFC were more effective in adolescent patients than in adults [106].

In relation to the evolution of the depressive episode as a predictor of response to TMS therapy, a trial revealed that a shorter duration of a depressive episode may predict response to HF-rTMS $(10 \mathrm{~Hz})$ over the left DLPFC since patients with a depressive episode duration of less than 4 years had a mean HAM-D decrease of 


\begin{tabular}{|c|c|c|c|c|c|}
\hline POSITIVE PREDICTOR & $\begin{array}{l}\text { NEGATIVE } \\
\text { PREDICTOR }\end{array}$ & TYPE OF TMS & $\begin{array}{l}\text { TARGET OF } \\
\text { STIMULATION }\end{array}$ & $\begin{array}{l}\text { MAXIMUM LEVEL } \\
\text { OF EVIDENCE* }\end{array}$ & $\begin{array}{l}\text { REFERENCE } \\
\text { (Author, Year, Ref) }\end{array}$ \\
\hline- & $\begin{array}{l}\text { - Treatment } \\
\text { refractoriness } \\
\text { - Older patients }\end{array}$ & HF-rTMS & Left DLPFC & $2 \mathrm{a}$ & [102] \\
\hline Younger patients (< 45 years) & - & LF-rTMS (1 Hz) & Right DLPFC & $2 \mathrm{~b}$ & [103] \\
\hline $\begin{array}{l}\text { - Low score of treatment resistance. } \\
\text { - Short duration of episode. } \\
\text { - High level of sleep disturbances. }\end{array}$ & - & $\begin{array}{l}\text { HF-rTMS }(20 \\
\mathrm{Hz})\end{array}$ & Left DLPFC & $2 \mathrm{~b}$ & [104] \\
\hline Duration of depressive episode (< 4 years) & - & $\begin{array}{l}\text { HF-rTMS (10 } \\
\mathrm{Hz})\end{array}$ & Left DLPFC & $2 \mathrm{~b}$ & [107] \\
\hline High extraversion levels & - & $\begin{array}{l}\text { HF-rTMS (10 } \\
\mathrm{Hz})\end{array}$ & Left DLPFC & $2 c$ & [109] \\
\hline $\begin{array}{l}\text { - Smaller deactivations in the anterior cingulate, the } \\
\text { left medial orbitofrontal and the right middle frontal } \\
\text { cortices. } \\
\text { - Larger activations in the left ventral-caudal putamen. }\end{array}$ & - & $\begin{array}{l}\text { HF-rTMS (15 } \\
\mathrm{Hz})\end{array}$ & Left DLPFC & $2 \mathrm{~b}$ & [111] \\
\hline Lower DLPFC/VMPFC CBF ratio & - & $\begin{array}{l}\text { HF-rTMS (10 } \\
\mathrm{Hz})\end{array}$ & Left DLPFC & $2 c$ & [134] \\
\hline Increased CBF in the ventromedial prefrontal cortex & - & LF-rTMS (1 Hz) & Right DLPFC & $2 c$ & [114] \\
\hline \multicolumn{6}{|c|}{ ABB: CBF: Cerebral blood flow; DLPFC: Dorsolateral prefrontal cortex; fMRI: Functional Magnetic Resonance Imaging; } \\
\hline \multicolumn{6}{|c|}{$\begin{array}{l}\text { HF-rTMS: High Frecuency rTMS; Hz: Hertz; fMRI: Functional Magnetic Resonance Imaging; LF-rTMS: Low Frecuency rTMS; MDD: Major Depressive } \\
\text { Disorders; rTMS: Repetitive Transcranial Magnetic Stimulation; VMPFC: Ventromedial prefrontal cortex. }\end{array}$} \\
\hline \multicolumn{6}{|c|}{ *"Levels of Evidence 1" of the Oxford Centre for Evidence-Based Medicine (OCEBM), Levels of Evidence Working Group (March 2009). } \\
\hline
\end{tabular}

$52 \%$ compared to $6 \%$ in those with an episode duration longer than 10 years [107]. Another interesting approach to this problem proposes to predict clinical response to rTMS by baseline lateral visual-field stimulation [108], or even by determining pre-treatment levels of extraversion and neuroticism [109].

The introduction of RMI to this type of studies has reported promising outcomes. In 2012, Furtado et al. [110] published a prospective study that, using daily treatment (five days a week) with HF-rTMS $(10 \mathrm{~Hz})$ over the left DLPFC for six weeks, with MRI and neuropsychological assessment, attempted to demonstrate whether the volume of the hippocampus and the amygdala, as well as the neurocognitive profile, could be used as predictors of response to treatment. In this regard, no differences were found in those parameters between responders and non-responders. Only a shorter pre-treatment in the left hippocampus volume showed a trend towards predicting eventual subjective improvement in depressive symptomatology [110]. Also making use of the fMRI, an RCT conducted with twenty-one depressive patients, who were randomized to sham rTMS or HFrTMS $(15 \mathrm{~Hz})$ over the left DLPFC, concluded that, in the active rTMS group, larger HAM-D reductions were significantly correlated with smaller deactivations during pre-treatment fMRI assessment in the anterior cingulate, the left medial orbitofrontal and the right middle frontal cortices, in addition to greater activations in the left ventral-caudal putamen [111]. Similarly, another study using MRI and positron emission tomography (PET) reported that both preserved left lateral orbitofrontal cortex volume and amygdala metabolism might precondition response to HF-rTMS $(10 \mathrm{~Hz})$ over prefrontal cortex in MDD [112].

In the same direction, it seems that both some patterns of cerebral perfusion and certain patterns of EEG may be linked to a more pronounced antidepressant response to rTMS therapy. Indeed, patients with a lower cerebral blood flow $(\mathrm{CBF})$ ratio of the DLPFC to the ventromedial prefrontal cortex may show a better response to HF-rTMS (10 Hz) over the left DLPFC [113]. Equally, depressed patients with increased $\mathrm{CBF}$ in the ventromedial prefrontal cortex and decreased $\mathrm{CBF}$ in the orbitofrontal cortex and the subgenual cingulate cortex may exhibit a better response to right prefrontal LF-rTMS (1 $\mathrm{Hz})[114,115]$. Moreover, a recent study showed that single pulse TMS to the left DLPFC using a unique TMS-fMRI set-up, triggered activity in the subgenual anterior cingulate cortex in four out of nine participants [116]. Nevertheless, it has been demonstrated that the changes in CBF after rTMS therapy may present a significant individual variability, making it difficult to analyze the results based on this parameter [117]. 
A later study showed that changes in frontal cerebral blood volume, measured as frontal hemoglobin concentration during TMS, are correlated with clinical outcomes of treatment [118].

Finally, some pilot studies suggest that certain EEG patterns could be useful as predictors, making it feasible to predict rTMS treatment efficacy of either treatment modality (HF-rTMS and LF-rTMS) with a specificity of $83 \%$ and a sensitivity of $78 \%$, for a combined accuracy of $80 \%$ using a statistical prediction model based on a mixture of factor analyses [119], even in the first week of rTMS [120]. A fact of note is that increased low-theta power in the subgenual anterior cyngulate cortex could also predict response to HF-rTMS $(10 \mathrm{~Hz})$ over left DLPFC in patients with vascular depression [121] and MDD [122]. Similarly, pretreatment alpha band power on parieto-temporal regions might be a predictor for response to HF-rTMS (10 $\mathrm{Hz}$ ) over the left DLPFC [123]; however, in this study the sample was a small one and the patients heterogeneous, so this result should be treated with caution. A later study suggested that $10 \mathrm{~Hz}$ motor cortex (MC) rTMS was predictive of the antidepressant effect of $10 \mathrm{~Hz}$ DLPFC rTMS [124].

\section{Low frequency rTMS versus High frequency rTMS}

While the majority of studies that have pointed to TMS therapy as being effective in the treatment of depression have been carried out using HFrTMS over the left DLPFC, in recent years, much evidence showing that the effects induced by LF-rTMS $(1 \mathrm{~Hz})$ over the right DLPFC can be comparable has been published. This effect of LF-rTMS has been known since more than ten years ago when preliminary studies reported antidepressant outcomes from this protocol $[22,125,126]$. From then until now, several works have been published corroborating the antidepressant effect of LF-rTMS (mainly $1 \mathrm{~Hz}$ ) to the right DLPFC in patients with depression [82,127-130]; this effect could be comparable to antidepressant drugs like venlafaxine [131].

Two recent meta-analyses collecting data from eight RCTs each one, (263 patients) [132] and (249 patients) [133], show major evidence for the beneficial effect of this form of rTMS in the treatment of MDD. These studies conclude that LF-rTMS $(1 \mathrm{~Hz})$ to the right DLPFC provides clinically meaningful benefits that are comparable to those of standard antidepressants and HF-rTMS [118] with fewer side effects [133].

Regardless of whether the final antidepressant effects are equal, those of both types of stimulation (LF-rTMS and HF-rTMS) on activity and brain metabolism, as well as on regional CBF, are completely different [134], besides their individual variability [117]. Globally, the majority of studies agree that HFrTMS induces a more extensive increase in brain activity and regional CBF, while LF-rTMS shows a slight decline in brain activity and regional $\mathrm{CBF}$ in much localized areas. These facts point to the different neurophysiological, and possibly neuropsychiatric, consequences of changing the rTMS frequency $[115,135,136]$.

Despite these differences with respect to changes in brain metabolism and CBF, there is no doubt that both therapies exert a benefit on mood. Various studies comparing the effect of both protocols concluded that they do not differ as regards their antidepressant power [128,137138]. Moreover, when only responder-totherapy patients were evaluated, equivalent brain single photon emission computed tomography (SPECT) perfusion changes underlying therapeutic efficiency of both protocols are found [140].

In conclusion, keeping in mind that there is no difference between the effectiveness of both rTMS protocols and that LF-rTMS sessions are shorter, possibly better tolerated and with fewer side effects, LF-rTMS to the right DLPFC is emerging as an even superior treatment alternative to HF-rTMS over the left DLPFC in MDD, particularly in bipolar patients with a higher anxiety degree [130].

\section{New trends and strategies in TMS and de-} pression

Once TMS therapy has shown itself to be effective and safe [1], new trends in the use of this technique have focused on discovering protocols and types of stimulation with greater effects and an equal safety. Therefore, changes in the frequency and the type of pulse, as well as structural modifications of TMS devices are being tested with that aim.

From the point of view of TMS devices, the introduction of a double-cone coil with large angled windings could allow direct stimulation of deeper areas such as the anterior cingulate 
cortex, thus increasing the likelihood of treatment success in some contexts [141]. 2-coil rTMS device over the left DLPFC prefrontal cortex and dorsomedial prefrontal cortex could possess episodic memory-enhancing capabilities [142]. With the same aim, the use of deep-TMS over the prefrontal cortex using H-coil improved both apathy and depression similarly, although it was unable to induce remission in patients with higher scores in apathy-related items of HAM-D. In this regard, it is suggested that this phenomenon should be investigated in order to predict the effectiveness of deep-TMS in MDD [143]. Other studies have also reported that deep-TMS may be beneficial in MDD, augmenting antidepressant medications and/or improving depressive symptoms [144,145].

Aside from the shape of the coil, improvements in its positioning might improve the antidepressant outcome of rTMS [146]. Thus, the introduction of neuronavigation equipment could ensure a better placement of the coil, eliminating the individual variability and improving the results obtained with this therapy [147-151]. The use of background EEG activity to determine stimulus timing as a means of improving rTMS efficacy has also proved useful [152].

From a different point of view, modifications of current standard protocols, as well as the use of other types of TMS, could open up a path towards the improvement of the effectiveness of TMS. In this regard, it has been suggested that ultra-HF-rTMS $(30 \mathrm{~Hz})$ over the left DLPFC might be a more effective protocol although, so far, this modality has only been seen to be a safe alternative that induces an improvement in processing speed performance, but not as a useful antidepressant therapy [153].

On the other hand, one of the disadvantages of rTMS treatment is the discomfort caused by current schemes based on daily sessions during two or four weeks, which often deters adherence to treatment. To solve this problem, accelerated TMS protocols, with the complete treatment administered over a few days, would have significant advantages in terms of access and patient acceptance. In this sense, preliminary studies suggest that accelerated TMS might afford an excellent safety profile with an efficacy comparable to that achieved in daily rTMS in other trials [154]. In the same way, another form of patterned-TMS protocol, TBS, has also demonstrated its safety, tolerability and preliminary evidence for antidepressant effectiveness when applied to the left or right DLPFC at different stimulation parameters [155].

Other alternatives to existing standard protocols are either combined sequential use of LFrTMS and HF-rTMS, or the application of one of those protocols bilaterally. In this latter regard, some RCTs support the hypothesis that sequential bilateral rTMS (LF-rTMS then HF-rTMS or vice versa) is effective and safe $[156,157]$, but not more effective than unilateral HF left-sided rTMS [158-160], or unilateral LF right-sided rTMS [160,161]. Thus, according to the conclusions of a meta-analysis conducted by Berlim et al. [162], who obtained data from seven RCTs (279 subjects), bilateral rTMS is a promising treatment for major depression as it provides clinically meaningful benefits that are comparable with those of standard antidepressants and unilateral rTMS. A metaanalysis with data obtained from 25 studies consisting of 1288 individuals with MDD, demonstrated that electroconvulsive therapy was the most efficacious, but least tolerated, treatment, LF-rTMS was the best tolerated treatment for MDD and bilateral rTMS appears to present the most favorable balance between efficacy and acceptability [163]. However, electroconvulsive therapy appears to result in a higher percentage of side effects compared with TMS treatment [164].

Another new scheme using frequency-modulated priming stimulation seems to increase the effect of rTMS therapy. A study carried out with forty patients with moderate-to-severe depression concluded that pre-stimulation with frequencymodulated priming stimulation in the theta range (4-8 Hz; 400 pulses) has a greater antidepressant effect than low-frequency stimulation alone [165]. Other previous trials using similar protocols corroborate these results $[166,167]$. Augmentative rTMS to the left dorsolateral prefrontal cortex at $120 \%$ motor threshold (10 $\mathrm{Hz}$, 4-second train duration), 3000 pulses per session using a figure-eight coil, with a minimum of 20 sessions during four weeks, was more effective on depression and anxiety symptoms than standard therapy (psychopharmacotherapy and psychotherapy) in MDD [168].

As a novel strategy in the use of TMS in MDD, some works have pointed to the usefulness of combining rTMS therapy and antidepressant drugs from the very first moment, just after the diagnosis of MDD, since this strategy might 
accelerate the antidepressant response in firstepisode onsets. This conclusion was reached in a study conducted with sixty young depressive patients who started treatment from the beginning with citalopram and sham or rTMS therapy during two weeks [169]; or a recent study with 281 depressed patients who had achieved stable full or partial remission on a 6-month antidepressant (ADP) run-in treatment and were randomly assigned to an rTMS $(n=91)$, ADP $(n=108)$, or combined (rTMS + ADP, $\mathrm{n}=82$ ) treatment group for 12 months in 5-10 sessions over a 3-5-day period/monthly. This study concluded that TMS, whether as a mono- or additional therapy, is superior to antidepressants in preventing depressive relapse/ recurrence, particularly in first-episode depressed patients [170].

Another study in 196 patients combining rTMS and psychotherapy, based on principles of cognitive behavioral therapy, during 10 sessions, resulted in a $66 \%$ response and a $56 \%$ remission rate at the end of the treatment, with $60 \%$ sustained remission at follow-up [160]. Russo et al [171] concluded that Incorporation of a modified version of Behavioral Activation therapy during transcranial magnetic stimulation is feasible, well tolerated, and holds a potential for augmenting the efficacy of TMS treatment for patients with treatment-resistant depression.

In conclusion, despite all this novel evidence, new RCTs are needed to compare the safety and antidepressant effect among these new devices, protocols and strategies, and the classic protocols (HF-rTMS 10 - $20 \mathrm{~Hz}$ over left DLPFC or LFrTMS $1 \mathrm{~Hz}$ over right DLPFC) prior to their introduction in daily clinical practice.

\section{Other Psychiatric Disorders}

As a consequence of the good therapeutic results obtained through the use of different TMSprotocols in depression and schizophrenia, many other studies have attempted to demonstrate a possible beneficial effect of this technique in other psychiatric disorders.

On the opposite side of depression is mania, a disorder included in some forms of bipolar disorder for which treatment with TMS is also in study. The first reference on this subject was published in 1998 [172]. That trial, comparing the use of HF-rTMS $(20 \mathrm{~Hz})$ on the right and left DLPFC, concluded that a more significant improvement was observed in patients treated with right than with left HF-rTMS. This finding led to proposing that the therapeutic effect of TMS in mania showed opposite laterality to that found in depression [172].

More recent studies assessing the usefulness of TMS in mania are contradictory. Thus, a trial using HF-rTMS $(20 \mathrm{~Hz})$ over the right DLPFC did not demonstrate that real stimulation was more effective than sham stimulation [173]. However, its authors report that the patients included in the study had a major psychotic component that could have interfered in the outcomes [173], since other similar studies support the positive effect of HF-rTMS over right DLPFC in mania [174-176]. Despite the latter, current evidence does not recommend a therapeutic use of TMS in mania, further investigations into this subject still being necessary in order to elucidate a possible role of this treatment in mania.

Related to mania, a specific problem in the use of TMS in psychiatric patients that has concerned researchers is the possibility that it induces treatment-emergent mania/hypomania (TEM). A meta-analysis focused on this eventuality revealed that rTMS treatment carries a slight risk of TEM that is not statistically higher than that associated with sham treatment [177]. Moreover, in those cases in which it appears, decrease or discontinuation of antidepressant and/or rTMS treatment and/or use of anti-manic medication can treat this complication effectively. Reducing the frequency of sessions from two per day to one could also reduce the likelihood of TEM recurrence [177].

Another disorder candidate for treatment with TMS is posttraumatic stress disorder (PTSD), a severe anxiety condition that can develops after exposure to any event that results in producing psychological trauma. Preliminary studies on the subject showed improvement of the core symptoms of PTSD (avoidance, anxiety and somatization) with a single session of LF-rTMS $(0.3 \mathrm{~Hz})$ over the motor cortex, although the effect was short and transient [178]. One of the latest RCTs (20 patients) conducted in this regard concluded that ten sessions of LF-rTMS $(1 \mathrm{~Hz})$ over the right DLPFC resulted in statistically and clinically significant improvements in core PTSD and depressive symptoms, compared with sham treatments, effects that lasted up to two months post-treatment [179]. Using the same stimulation pattern, similar outcomes were found by Nam et al. [180]. 
In the same line, studies with HF-rTMS (10 $\mathrm{Hz}$ ) over the right DLPFC have shown a greater therapeutic effect on core symptoms (re-experiencing and avoidance), and on the relief of anxiety, than LF-rTMS (1 Hz)[181]. Furthermore, another study that evaluated the effect of HF-rTMS $(20 \mathrm{~Hz})$ on both right and left DLPFC in patients with PTSD allowed one to elucidate that this therapy applied to the right side may be more beneficial for anxiety control and core symptoms, while it showed a significantly greater effect on mood when applied on the left [182]. Other authors have also reported this latter effect [183]. Based on this background, some authors have theorized that daily applications of HF-rTMS in PTSD patients may reduce access to the set of autobiographical stored events that, if re-experienced, may cause the overt PTSD symptoms [184]. However, this theory has not been proven yet.

Regarding another anxiety disorder, obsessivecompulsive disorder (OCD), the available literature is as scant as it is interesting. In 2003, Martin et al. [185] carried out a Cochrane review analyzing the possible effect of TMS on patients with OCD. Three RCTs were included in the analysis but only two contained data in a suitable form for quantitative analysis which, finally, was not possible. Therefore, no conclusion on the efficacy of TMS in the treatment of OCD was drawn [185]. On the contrary, in 2013, a meta-analysis conducted by Berlim et al. [186] including data from ten RCTs (282 subjects) has revealed more promising outcomes. Those authors concluded that, following a mean of 14 sessions, rTMS seems to be effective in treating OCD-related symptoms mainly when LF-rTMS and protocols targeting non-DLPFC areas (orbitofrontal cortex or supplementary motor area (SMA)) are applied. HF-rTMS placed over the DLPFC does not seem to be more effective than sham rTMS [186]. In addition, in their opinion, rTMS could be as effective as other second- or third-line pharmacological strategies for OCD with fewer metabolic adverse effects. TMS could be used to facilitate the response to medication for which dose increases for the patient are not possible [187]. TMS DLPFC during the viewing of symptom-provoking stimuli may facilitate the response to subsequent cognitive behavioral therapy [188].

Future studies will help to elucidate the role that rTMS could play in the treatment of PTSD and OCD. New RCTs will be necessary to clarify the most adequate and effective protocol for these patients, as well as the impact of new neuromodulation devices.

Finally, almost anecdotally, TMS has been used and might open up new fields of research in children with Tourette's syndrome [189,190] and psychogenic movement disorders [191]. Furthermore, there are an increasing number of works suggesting that TMS may have a role in the treatment for dependency on drugs such as alcohol [192], tobacco [193-196] or opioids [197]; showing once more, the therapeutic potential of an emerging technique in constant evolution.

\section{Conclusions}

In summary, TMS is presented as a novel, powerful, non-invasive therapeutic strategy in psychiatric disorders. This therapy appears to modulate several biochemical processes that might be involved in its therapeutic effects. Regarding the clinical evidence of the use of TMS in psychiatry (Table 2) we can conclude that:

Depression represents the paradigm of the therapeutic effectiveness of TMS in psychiatric diseases. In addition, a great deal of evidence shows beneficial effects of this therapy on AVH of schizophrenia, as well as on the symptomatology of other psychiatric disorders such as PTSD or OCD.

In spite of the excellent outcomes reaped by TMS as a therapy so far, this should be still considered as an emerging technique and, therefore, new RCTs are needed to clarify its role in the treatment of psychiatric disorders and how new protocols and technologies might improve the results obtained by this novel therapy.

\section{Conflict of Interest}

The authors report no conflict of interest.

\section{Abbreviations}

AD:Alzheimer's disease; AVH: Auditory verbal hallucinations; BDNF: Brain-derived neurotrophic factor; CBF: Cerebral blood flow; cTBS: Continuous theta burst stimulation; DLPFC: Dorsolateral prefrontal cortex; ECT: Electroconvulsive therapy; EEG: Electroencephalography; EL-EMF: Extremely low-electromagnetic field; FDA: U. S. Food and Drug Administration; HAM-D: Hamilton Rating Scale for Depression; HD: Huntington's disease; HF-rTMS: High frequency repetitive transcranial magnetic stimulation; iTBS: 


\begin{tabular}{|c|c|c|c|c|c|}
\hline CLINICAL EFFECT & DISORDER & TYPE OF TMS & TARGET OF STIMULATION & $\begin{array}{l}\text { MAXIMUM LEVEL OF } \\
\text { EVIDENCE* }\end{array}$ & $\begin{array}{l}\text { REFERENCE } \\
\text { (Author, Year, Ref) }\end{array}$ \\
\hline \multirow{3}{*}{ Reduction of AVH } & \multirow{3}{*}{ Schizophrenia } & cTBS & Left temporoparietal cortex & $2 \mathrm{~b}$ & [41] \\
\hline & & $\begin{array}{l}\text { LF-rTMS } \\
(1 \mathrm{~Hz})\end{array}$ & Left temporoparietal cortex & $1 \mathrm{a}$ & [24] \\
\hline & & $\begin{array}{l}\text { Guided-fRMI HF- } \\
\text { rTMS } \\
(20 \mathrm{~Hz})\end{array}$ & Left superior temporal sulcus & 4 & [25] \\
\hline Decrease hypofrontality & Schizophrenia & $\begin{array}{l}\text { HF-rTMS } \\
(10 \mathrm{~Hz})\end{array}$ & Left DLPCF & $1 b$ & [19] \\
\hline $\begin{array}{l}\text { Improvement on positive } \\
\text { and psychotic symptoms }\end{array}$ & Schizophrenia & $\begin{array}{l}\text { Alpha-EEG-guided } \\
\text { rTMS }\end{array}$ & $\begin{array}{l}\text { Bilateral frontal or parietal } \\
\text { cortex }\end{array}$ & $2 \mathrm{~b}$ & [18] \\
\hline \multirow{2}{*}{$\begin{array}{l}\text { Improvement on } \\
\text { negative symptoms }\end{array}$} & \multirow{2}{*}{ Schizophrenia } & \multirow{2}{*}{$\begin{array}{l}\text { HF-rTMS } \\
(10 \mathrm{~Hz})\end{array}$} & Left DLPFC & $1 \mathrm{a}$ & [30] \\
\hline & & & Bilateral prefrontal & $1 b$ & [42] \\
\hline $\begin{array}{l}\text { Reduction of tobacco } \\
\text { craving }\end{array}$ & Schizophrenia & $\begin{array}{l}\text { HF-rTMS } \\
(20 \mathrm{~Hz})\end{array}$ & Bilateral DLPFC & $2 \mathrm{~b}$ & [195] \\
\hline $\begin{array}{l}\text { Reduction of cigarette } \\
\text { consumption }\end{array}$ & Schizophrenia & $\begin{array}{l}\text { HF-rTMS } \\
(10 \mathrm{~Hz})\end{array}$ & Left DLPFC & $2 \mathrm{~b}$ & [196] \\
\hline \multirow{10}{*}{ Antidepressant effect } & \multirow{5}{*}{ MDD } & $\begin{array}{l}\text { HF-rTMS } \\
(10-20 \mathrm{~Hz})\end{array}$ & Left DLPFC & $1 \mathrm{a}$ & [77] \\
\hline & & $\begin{array}{l}\text { LF-rTMS } \\
(1 \mathrm{~Hz})\end{array}$ & Right DLPFC & $1 \mathrm{a}$ & [132] \\
\hline & & Deep TMS & Prefrontal cortex & 4 & [145] \\
\hline & & $\begin{array}{l}\text { Sequential } \\
\text { bilateral rTMS }\end{array}$ & Left and right DLPFC & $1 \mathrm{~b}$ & [157] \\
\hline & & rTMS & Bilateral DLPFC & $1 \mathrm{a}$ & [162] \\
\hline & PD & $\begin{array}{l}\text { HF-rTMS } \\
(5 \mathrm{~Hz})\end{array}$ & Left DLPFC & $2 \mathrm{~b}$ & [94] \\
\hline & $\begin{array}{l}\text { Postpartum } \\
\text { depression }\end{array}$ & $\begin{array}{l}\text { HF-rTMS } \\
(5 \mathrm{~Hz})\end{array}$ & Left DLPFC & $2 \mathrm{~b}$ & [97] \\
\hline & Panic Disorder & $\begin{array}{l}\text { LF-rTMS } \\
(1 \mathrm{~Hz})\end{array}$ & Right DLPFC & 4 & [98] \\
\hline & OCD & $\begin{array}{l}\text { HF-rTMS } \\
(10 \mathrm{~Hz})\end{array}$ & Right DLPFC & $2 \mathrm{~b}$ & [99] \\
\hline & Fibromyalgia & $\begin{array}{l}\text { LF-rTMS } \\
(1 \mathrm{~Hz})\end{array}$ & Right DLPFC & $2 \mathrm{~b}$ & [101] \\
\hline $\begin{array}{l}\text { Amelioration of } \\
\text { psychomotor symptoms }\end{array}$ & MDD & $\begin{array}{l}\text { HF-rTMS } \\
(10 \mathrm{~Hz})\end{array}$ & Left DLPFC & 4 & [80] \\
\hline \multirow{3}{*}{$\begin{array}{l}\text { Positive effect on } \\
\text { cognitive function }\end{array}$} & \multirow{2}{*}{ MDD } & $\begin{array}{l}\text { LF-rTMS } \\
(1 \mathrm{~Hz})\end{array}$ & Right DLPFC & 4 & [82] \\
\hline & & $\begin{array}{l}\text { HF-rTMS } \\
(10 \mathrm{~Hz})\end{array}$ & Left DLPFC & 4 & [86] \\
\hline & Schizophrenia & iTBS & Cerebellar vermal & 4 & [36] \\
\hline $\begin{array}{l}\text { Amelioration of mania } \\
\text { symptoms }\end{array}$ & Bipolar disorder & $\begin{array}{l}\text { HF-rTMS } \\
(20 \mathrm{~Hz})\end{array}$ & Right DLPFC & $2 \mathrm{~b}$ & [176] \\
\hline \multirow{2}{*}{$\begin{array}{l}\text { Improvement of core } \\
\text { symptoms }\end{array}$} & \multirow{2}{*}{ PTSD } & $\begin{array}{l}\text { HF-rTMS } \\
(20 \mathrm{~Hz})\end{array}$ & Right DLPFC & $2 \mathrm{~b}$ & [182] \\
\hline & & $\begin{array}{l}\text { LF-rTMS } \\
(1 \mathrm{~Hz})\end{array}$ & Right DLPFC & $2 \mathrm{~b}$ & [179] \\
\hline $\begin{array}{l}\text { Anti-obsessive } \\
\text { (Improvement YBOCS) }\end{array}$ & OCD & $\begin{array}{l}\text { rTMS } \\
\text { (LF-rTMS 1Hz) }\end{array}$ & SMA or orbitofrontal cortex & $1 \mathrm{a}$ & [186] \\
\hline \multicolumn{6}{|c|}{$\begin{array}{l}\text { ABB: AVH: Auditory verbal hallucinations; cTBS: Continuous theta burst stimulation; DLPFC: Dorsolateral prefrontal cortex; fMRI: Functional Magnet } \\
\text { Resonance Imaging; HF-rTMS: High Frecuency rTMS; Hz: Hertz; iTBS: intermittent theta burst stimulation; LF-rTMS: Low Frecuency rTMS; MDD: Maj } \\
\text { Depressive Disorders; OCD: Obsessive-compulsive disorder; PD: Parkinson's disease; PTSD: Posttraumatic stress disorder; rTMS: Repetitive Transcrani } \\
\text { Magnetic Stimulation; SMA: Supplementary motor area; YBOCS: Yale Brown Obsessive Compulsive Scale. }\end{array}$} \\
\hline \multicolumn{6}{|c|}{ * "Levels of Evidence 1" of the Oxford Centre for Evidence-Based Medicine (OCEBM), Levels of Evidence Working Group (March 2009). } \\
\hline
\end{tabular}


Intermittent theta burst stimulation; LF-rTMS: Low Frequency repetitive transcranial magnetic stimulation; MDD: Major depressive disorder; MRI: Magnetic Resonance Imaging; OCD: Obsessive-compulsive disorder PD: Parkinson's disease; PET: Positron emission tomography; PTSD: Posttraumatic stress disorder; RCT:Randomized controlled trial; fRMI: Functional magnetic resonance imaging; SMA:
Supplementary motor area; SNRIs: Serotoninnorepinephrine reuptake inhibitors; SPECT: Single photon emission computed tomography; SSRIs: Selective serotonin re-uptake inhibitors;

TBS: Theta burst stimulation; TEM: Treatmentemergent mania/hypomania; TMS: Transcranial magnetic stimulation; rTMS: Repetitive transcranial magnetic stimulation.

\section{References}

1. Rossi S, Hallett M, Rossini PM, et al. Safety, ethical considerations, and application guidelines for the use of transcranial magnetic stimulation in clinical practice and research. Clin. Neurophysiol 120(2), 2008-2039 (2009).

2. Lefaucheur JP. Principles of therapeutic use of transcranial and epidural cortical stimulation. Clin. Neurophysiol 119(10), 2179-2184 (2008)

3. Medina FJ, Tunez I. Mechanisms and pathways underlying the therapeutic effect of transcranial magnetic stimulation. Rev. Neurosci 24(5), 507-525 (2013).

4. Kim DR, Pesiridou A, O'Reardon JP. Transcranial magnetic stimulation in the treatment of psychiatric disorders. Curr. Psychiatry Rep 11(6), 447-52 (2009).

5. Mouri A, Nagai T, Ibi D, et al. Animal models of schizophrenia for molecular and pharmacological intervention and potentia candidate molecules. Neurobiol. Dis 53(1), 61-74 (2012).

6. Goto Y, Grace AA. The dopamine system and the pathophysiology of schizophrenia: a basic science perspective. Int. Rev. Neurobiol 78(1), 41-68 (2007)

7. Lang UE, Puls I, Muller DJ, et al. Molecular mechanisms of schizophrenia. Cell. Physiol. Biochem 20(6), 687-702 (2007).

8. Hasan A, Falkai P, Wobrock T. Transcranial brain stimulation in schizophrenia: targeting cortical excitability, connectivity and plasticity. Curr. Med. Chem 20(3), 405413 (2013).

9. Favalli G, Li J, Belmonte-de-Abreu P, et al. The role of BDNF in the pathophysiology and treatment of schizophrenia. J. Psychiatr. Res 46(1), 1-11 (2012).

10. Richard MD, Brahm NC. Schizophrenia and the immune system: pathophysiology, prevention, and treatment. Am. J. Health Syst. Pharm 69(9), 757-766 (2012).

11. Watanabe Y, Someya T, Nawa H. Cytokine hypothesis of schizophrenia pathogenesis: evidence from human studies and animal models. Psychiatry Clin. Neurosci 64(3), 217230 (2010).
12. Wood SJ, Yucel M, Pantelis C, et al. Neurobiology of schizophrenia spectrum disorders: the role of oxidative stress. Ann. Acad. Med. Singapore 38(5), 396-396 (2009).

13. Yao JK, Keshavan MS. Antioxidants, redox signaling, and pathophysiology in schizophrenia: an integrative view. Antioxid. Redox. Signal 15(7), 2011-2035 (2011)

14. Horacek J, Brunovsky M, Novak T, et al. Effect of low-frequency rTMS on electromagnetic tomography (LORETA) and regional brain metabolism (PET) in schizophrenia patients with auditory hallucinations. Neuropsychobiology 55(3-4), 132-142 (2007).

15. Kindler J, Homan P, Jann K, et al. Reduced Neuronal Activity in Language-Related Regions After Transcranial Magnetic Stimulation Therapy for Auditory Verbal Hallucinations. Biol. Psychiatry 73(6), 518524 (2012).

16. Homan P, Kindler J, Hauf M, et al. Cerebral blood flow identifies responders to transcranial magnetic stimulation in auditory verbal hallucinations. Transl. Psychiatry 2(11), e189 (2012).

17. Barr MS, Farzan F, Arenovich T, et al. The effect of repetitive transcranial magnetic stimulation on gamma oscillatory activity in schizophrenia. PLoSOne 6(7), e22627 (2011).

18. Jin Y, Kemp AS, Huang Y, et al. Alpha EEG guided TMS in schizophrenia. Brain. Stimul 5(4), 560-568 (2012)

19. Kamp D, Brinkmeyer J, Agelink MW, et al. High frequency repetitive transcranial magnetic stimulation (rTMS) reduces EEG-hypofrontality in patients with schizophrenia. Psychiatry. Res 236, 199-201 (2016).

20. Farzan F, Barr MS, Sun Y, et al. Transcranial magnetic stimulation on the modulation of gamma oscillations in schizophrenia. Ann. N. Y. Acad. Sci 1265(1), 25-35 (2012).

21. Geller V, Grisaru N, Abarbanel JM, et al. Slow magnetic stimulation of prefrontal cortex in depression and schizophrenia. Prog. Neuropsychopharmacol. Biol. Psychiatry 21(1), 105-110 (1997).

22. Feinsod M, Kreinin B, Chistyakov A, et al. Preliminary evidence for a beneficial effect of low-frequency, repetitive transcranial magnetic stimulation in patients with major depression and schizophrenia. Depress. Anxiety 7(2), 65-68 (1998).

23. Blumberger DM, Fitzgerald PB, Mulsant $\mathrm{BH}$, et al. Repetitive transcranial magnetic stimulation for refractory symptoms in schizophrenia. Curr. Opin. Psychiatry 23(2), 85-90 (2010).

24. Slotema CW, Aleman A, Daskalakis ZJ, et al. Meta-analysis of repetitive transcranial magnetic stimulation in the treatment of auditory verbal hallucinations: Update and effects after one month. Schizophr. Res 142(1-3), 40-45 (2012).

25. Montagne-Larmurier A, Etard O, Razafimandimby A, et al. Two-day treatment of auditory hallucinations by high frequency rTMS guided by cerebral imaging: a 6 month follow-up pilot study. Schizophr. Res 113(1), 77-83 (2009).

26. Aleman A, Sommer IE, Kahn RS. Efficacy of slow repetitive transcranial magnetic stimulation in the treatment of resistant auditory hallucinations in schizophrenia: a meta-analysis. J. Clin. Psychiatry 68(3), 416421 (2007).

27. Tranulis C, Sepehry AA, Galinowski A, et al. should we treat auditory hallucinations with repetitive transcranial magnetic stimulation? A metaanalysis. Can. J. Psychiatry 53(9), 577-586 (2008).

28. Freitas C, Fregni F, Pascual-Leone A. Meta-analysis of the effects of repetitive transcranial magnetic stimulation (rTMS) on negative and positive symptoms in schizophrenia. Schizophr. Res 108(1-3), 1124 (2009).

29. Dollfus S, Lecardeur L, Morello R, et al. Placebo response in repetitive transcranial magnetic stimulation trials of treatment of auditory hallucinations in schizophrenia: a meta-analysis. Schizophr. Bull 42(2), 301-308 (2016).

30. Dlabac-de Lange JJ, Knegtering R, et al. Repetitive transcranial magnetic stimulation for negative symptoms of schizophrenia: review and meta-analysis. J. Clin. Psychiatry 71(4), 411-418 (2010).

31. Aleman A, Enriquez-Geppert S, Knegtering 
$H$, et al. Moderate effects of noninvasive brain stimulation of the frontal cortex for improving negative symptoms in schizophrenia: Meta-analysis of controlled trials. Neurosci. Biobehav. Rev 89(1), 111-118 (2018).

32. Shi C, Yu X, Cheung EF, et al. Revisiting the therapeutic effect of rTMS on negative symptoms in schizophrenia: a metaanalysis. Psychiatry Res 215(5), 505-513 (2014).

33. Wobrock T, Guse B, Cordes J, et al. Left prefrontal high-frequency repetitive transcranial magnetic stimulation for the treatment of schizophrenia with predominant negative symptoms: a shamcontrolled, randomized multicenter trial. Biol. Psychiatry 77(11), 979-988 (2015).

34. Dougall N, Maayan N, Soares-Weiser K, et al. Transcranial magnetic stimulation (TMS) for schizophrenia. Cochrane. Database. Syst. Rev 2015(8), CD006081 (2015).

35. Garg S, Goyal N, Tikka SK, et al. Exacerbation of auditory verbal hallucinations with adjunctive high-frequency cerebellar vermal repetitive transcranial magnetic stimulation in schizophrenia: a case report. J. ECT 29(1), 65-66 (2013).

36. Demirtas-Tatlidede A, Freitas C, Cromer JR, et al. Safety and proof of principle study of cerebellar vermal theta burst stimulation in refractory schizophrenia. Schizophr. Res 124(1-3), 91-100 (2010).

37. Cardenas-Morales L, Nowak DA, Kammer T, et al. Mechanisms and applications of thetaburst rTMS on the human motor cortex. Brain. Topogr 22(4), 294-306 (2010).

38. Poulet E, Brunelin J, Ben Makhlouf W, et al. A case report of CTBS for the treatment of auditory hallucinations in a patient with schizophrenia. Brain. Stimul 2(2), 118-119 (2009).

39. Sidhoumi D, Braha S, Bouaziz N, et al. Evaluation of the therapeutic effect of theta burst stimulation on drug-resistant auditory hallucinations in a schizophrenic patient and its impact on cognitive function and neuronal excitability: a case study. Clin. Neurophysiol 121(5), 802 (2010).

40. Eberle MC, Wildgruber D, Wasserka B, et al. Relief from chronic intractable auditory hallucinations after long-term bilateral theta burst stimulation. Am. J. Psychiatry 167(11), 1410 (2010).

41. Kindler J, Homan P, Flury R, et al. Theta burst transcranial magnetic stimulation for the treatment of auditory verbal hallucinations: results of a randomized controlled study. Psychiatry. Res 209(1), 114-117 (2013).

42. Dlabac-de Lange JJ, Bais L, van Es FD, et al. Efficacy of bilateral repetitive transcranial magnetic stimulation for negative symptoms of schizophrenia: results of a multicenter double-blind randomized controlled trial. Psychol. Med 45(6), 12631275 (2015).

43. Krishnan V, Nestler EJ. The molecular neurobiology of depression. Nature 455(7215), 894-902 (2008).

44. Palazidou E. The neurobiology of depression. Br. Med. Bull 101(1), 127-145 (2012).

45. Tasset I, Pena J, Jimena I, et al. Effect of 17 beta-estradiol on olfactory bulbectomyinduced oxidative stress and behavioral changes in rats. Neuropsychiatr. Dis Treat 4(2), 441-449 (2008).

46. Tasset I, Medina FJ, Pena J, et al. Olfactory bulbectomy induced oxidative and cell damage in rat: protective effect of melatonin. Physiol. Res 59(1), 105-112 (2010).

47. Tunez I, Drucker-Colin R, Montilla P, et al. Protective effect of nicotine on oxidative and cell damage in rats with depression induced by olfactory bulbectomy. Eur. J. Pharmacol 627(1-3), 115-118 (2010).

48. Tasset I, Drucker-Colin R, Pena J, et al. Antioxidant-like effects and protective action of transcranial magnetic stimulation in depression caused by olfactory bulbectomy. Neurochem. Res 35(8), 11821187 (2010)

49. Zyss T, Gorka Z, Kowalska M, et al. Preliminary comparison of behavioral and biochemical effects of chronic transcranial magnetic stimulation and electroconvulsive shock in the rat. Biol. Psychiatry 42(10), 920924 (1997).

50. Fleischmann A, Prolov K, Abarbanel J, et $a l$. The effect of transcranial magnetic stimulation of rat brain on behavioral models of depression. Brain. Res 699(1), 130-132 (1995).

51. Schmidt HD, Shelton RC, Duman RS. Functional biomarkers of depression: diagnosis, treatment, and pathophysiology. Neuropsychopharmacology 36(12), 23752394 (2011).

52. Nibuya M, Morinobu S, Duman RS. Regulation of BDNF and trkB mRNA in rat brain by chronic electroconvulsive seizure and antidepressant drug treatments. J. Neurosci 15(11), 7539-7547 (1995).

53. Muller MB, Toschi N, Kresse AE, et al. Long-term repetitive transcranial magnetic stimulation increases the expression of brain-derived neurotrophic factor and cholecystokinin mRNA, but not neuropeptide tyrosine mRNA in specific areas of rat brain. Neuropsychopharmacology 23(2), 205-215 (2000).

54. Zheng H, Zhang L, Li L, et al. High- frequency rTMS treatment increases left prefrontal myo-inositol in young patients with treatment-resistant depression. Prog. Neuropsychopharmacol. Biol. Psychiatry 34(7), 1189-1195 (2010).

55. Szuba MP, O'Reardon JP, Rai AS, et al. Acute mood and thyroid stimulating hormone effects of transcranial magnetic stimulation in major depression. Biol. Psychiatry 50(1), 22-27 (2001)

56. Kito S, Hasegawa T, Fujita K, et al. Changes in hypothalamic-pituitary-thyroid axis following successful treatment with lowfrequency right prefrontal transcranial magnetic stimulation in treatment-resistant depression. Psychiatry. Res 175(1-2), 74-77 (2010).

57. Baeken C, De Raedt R, Leyman L, et al. The impact of one HF-rTMS session on mood and salivary cortisol in treatment resistant unipolar melancholic depressed patients. J. Affect. Disord 113(1-2), 100-108 (2009).

58. Evers S, Hengst K, Pecuch PW. The impact of repetitive transcranial magnetic stimulation on pituitary hormone levels and cortisol in healthy subjects. J. Affect. Disord 66(1), 83-88 (2001).

59. Hedges DW, Salyer DL, Higginbotham BJ, et al. Transcranial magnetic stimulation (TMS) effects on testosterone, prolactin, and corticosterone in adult male rats. Biol. Psychiatry 51(5), 417-421 (2002).

60. Reid PD, Pridmore S. Dexamethasone suppression test reversal in rapid transcranial magnetic stimulation-treated depression. Aust. N. Z. J. Psychiatry 33(2), 274-277 (1999).

61. Pridmore S. Rapid transcranial magnetic stimulation and normalization of the dexamethasone suppression test. Psychiatry Clin. Neurosci 53(1), 33-37 (1997).

62. Baeken C, De Raedt R. Neurobiological mechanisms of repetitive transcranial magnetic stimulation on the underlying neurocircuitry in unipolar depression. Dialogues. Clin. Neurosci 13(1), 139-145 (2011)

63. Pascual-Leone A, Rubio B, Pallardo F, et al. Rapid-rate transcranial magnetic stimulation of left dorsolateral prefrontal cortex in drug-resistant depression. Lancet 348(9022), 233-237 (1996).

64. George MS, Wassermann EM, Williams WA, et al. Daily repetitive transcranial magnetic stimulation (rTMS) improves mood in depression. Neuroreport 6(14), 1853-1856 (1995).

65. Conca A, Koppi S, Konig P, et al. Transcranial magnetic stimulation: a novel antidepressive strategy? Neuropsychobiology 34(4), 204-207 (1996).

66. Holtzheimer PE, Russo J, Avery DH. A meta- 
analysis of repetitive transcranial magnetic stimulation in the treatment of depression. Psychopharmacol. Bull 35(4), 149-169 (2001).

67. Martin JL, Barbanoj MJ, Schlaepfer TE, et al. Repetitive transcranial magnetic stimulation for the treatment of depression. Systematic review and meta-analysis. Br. J. Psychiatry 182(6), 4804-91 (2003).

68. Couturier JL. Efficacy of rapid-rate repetitive transcranial magnetic stimulation in the treatment of depression: a systematic review and meta-analysis. J. Psychiatry. Neurosci 30(2), 83-90 (2005).

69. Loo CK, Mitchell PB. A review of the efficacy of transcranial magnetic stimulation (TMS) treatment for depression, and current and future strategies to optimize efficacy. J. Affect. Disord 88(3), 255-267 (2005).

70. Gross M, Nakamura L, Pascual-Leone A, et al. Has repetitive transcranial magnetic stimulation (rTMS) treatment for depression improved? A systematic review and metaanalysis comparing the recent vs. the earlier rTMS studies. Acta Psychiatr. Scand 116(3), 165-173 (2007).

71. Berlim MT, van den Eynde F, TovarPerdomo S, et al. Response, remission and drop-out rates following high-frequency repetitive transcranial magnetic stimulation (rTMS) for treating major depression: a systematic review and meta-analysis of randomized, double-blind and shamcontrolled trials. Psychol. Med 44(2), 225-239 (2014).

72. Connolly RK, Helmer A, Cristancho MA, et al. Effectiveness of transcranial magnetic stimulation in clinical practice post-FDA approval in the United States: results observed with the first 100 consecutive cases of depression at an academic medical center. J. Clin. Psychiatry 73(4), e567-e573 (2012).

73. Ray S, Nizamie SH, Akhtar S, et al. Efficacy of adjunctive high frequency repetitive transcranial magnetic stimulation of left prefrontal cortex in depression: a randomized sham controlled study. J. Affect. Disord 128(1-2), 153-159 (2011).

74. Dell'osso B, Camuri G, Castellano F, et al. Meta-Review of Metanalytic Studies with Repetitive Transcranial Magnetic Stimulation (rTMS) for the Treatment of Major Depression. Clin. Pract. Epidemiol. Ment. Health 7(1), 167-177 (2011).

75. Berlim MT, McGirr A, Beaulieu MM, et al. High frequency repetitive transcranial magnetic stimulation as an augmenting strategy in severe treatment-resistant major depression: a prospective 4-week naturalistic trial. J. Affect. Disord 130(1-2), 312-317 (2011).

76. Schutter DJ. Antidepressant efficacy of high-frequency transcranial magnetic stimulation over the left dorsolateral prefrontal cortex in double-blind shamcontrolled designs: a meta-analysis. Psychol. Med 39(1), 65-75 (2009).

77. Berlim MT, Van den Eynde F, Daskalakis ZJ. High-frequency repetitive transcranial magnetic stimulation accelerates and enhances the clinical response to antidepressants in major depression: a meta-analysis of randomized, double-blind, and sham-controlled trials. J. Clin. Psychiatry 74(2), e122-e129 (2013).

78. Rumi DO, Gattaz WF, Rigonatti SP, et al. Transcranial magnetic stimulation accelerates the antidepressant effect of amitriptyline in severe depression: a double-blind placebo-controlled study. Biol. Psychiatry 57(2), 162-166 (2005).

79. Schrijvers DL, Baeken C, De Raedt R, et al. The Impact of High-Frequency Repetitive Transcranial Magnetic Stimulation on Fine Motor Functions in Medication-Resistant Major Depression. Neuropsychobiology 66(4), 252-258 (2012).

80. Baeken C, De Raedt R, Santermans L, et al. HF-rTMS treatment decreases psychomotor retardation in medicationresistant melancholic depression. Prog. Neuropsychopharmacol. Biol. Psychiatry 34(4), 684-687 (2010)

81. Little JT, Kimbrell TA, Wassermann EM, et al. Cognitive effects of 1- and 20-hertz repetitive transcranial magnetic stimulation in depression: preliminary report. Neuropsychiatry. Neuropsychol. Behav. Neurol 13(2), 119-124 (2000).

82. Pallanti S, Di Rollo A, Antonini S, et al. Low-frequency rTMS over right dorsolateral prefrontal cortex in the treatment of resistant depression: cognitive improvement is independent from clinical response, resting motor threshold is related to clinical response. Neuropsychobiology 65(4), 227-235 (2012).

83. Kuroda $\mathrm{Y}$, Motohashi $\mathrm{N}$, Ito $\mathrm{H}$, et al. Effects of repetitive transcranial magnetic stimulation on [11C]raclopride binding and cognitive function in patients with depression. J. Affect. Disord 95(1-3), 35-42 (2006).

84. Martis B, Alam D, Dowd SM, et al. Neurocognitive effects of repetitive transcranial magnetic stimulation in severe major depression. Clin. Neurophysiol 114(6), 1125-1132 (2003).

85. O'Connor MG, Jerskey BA, Robertson EM, et al. The effects of repetitive transcranial magnetic stimulation (rTMS) on procedural memory and dysphoric mood in patients with major depressive disorder. Cogn. Behav. Neurol 18(4), 223-227 (2005).

86. Kedzior KK, Rajput V, Price G, et al. Cognitive correlates of repetitive transcranial magnetic stimulation (rTMS) in treatmentresistant depression--a pilot study. BMC. Psychiatry 12, 163 (2012).

87. Mantovani A, Pavlicova M, Avery D, et al. Long-term efficacy of repeated daily prefrontal transcranial magnetic stimulation (TMS) in treatmnt-resistant depression. Depress. Anxiety 29(10), 883-890 (2012).

88. Janicak PG, Nahas Z, Lisanby SH, et al. Durability of clinical benefit with transcranial magnetic stimulation (TMS) in the treatment of pharmacoresistant major depression: assessment of relapse during a 6-month, multisite, open-label study. Brain. Stimul 3(4), 187-199 (2010).

89. Mayer G, Aviram S, Walter G, et al. Longterm follow-up of adolescents with resistant depression treated with repetitive transcranial magnetic stimulation. J. ECT 28(2), 84-86 (2012).

90. Fitzgerald PB, Grace N, Hoy KE, et al. An open label trial of clustered maintenance rTMS for patients with refractory depression. Brain. Stimul 6(3), 292-297 (2013).

91. Charnsil C, Suttajit S, Boonyanaruthee V, et al. Twelve-month, prospective, open-label study of repetitive transcranial magnetic stimulation for major depressive disorder in partial remission. Neuropsychiatr. Dis. Treat 8(1), 393-397 (2012).

92. Wang $\mathrm{H}$, Xue $\mathrm{Y}$, Chen $\mathrm{Y}$, et al. Efficacy of repetitive transcranial magnetic stimulation in the prevention of relapse of depression: study protocol for a randomized controlled trial. Trials 14(1), 338 (2013).

93. Lam RW, Chan P, Wilkins-Ho M, et al. Repetitive transcranial magnetic stimulation for treatment-resistant depression: a systematic review and metaanalysis. Can. J. Psychiatry 53(9), 621631 (2008).

94. Pal E, Nagy F, Aschermann Z, et al. The impact of left prefrontal repetitive transcranial magnetic stimulation on depression in Parkinson's disease: a randomized, double-blind, placebocontrolled study. Mov. Disord 25(14), 23112317 (2010).

95. Fregni F, Santos CM, Myczkowski ML, et al. Repetitive transcranial magnetic stimulation is as effective as fluoxetine in the treatment of depression in patients with Parkinson's disease. J. Neurol. Neurosurg. Psychiatry 75(8), 1171-1174 (2004).

96. Garcia KS, Flynn P, Pierce KJ, et al. Repetitive transcranial magnetic stimulation treats postpartum depression. Brain. Stimul 3(1), 36-41 (2010).

97. Myczkowski ML, Dias AM, Luvisotto T, et al. Effects of repetitive transcranial magnetic 
stimulation on clinical, social, and cognitive performance in postpartum depression. Neuropsychiatr. Dis. Treat 8(1), 491-500 (2012).

98. Mantovani A, Lisanby SH, Pieraccini F, et al. Repetitive Transcranial Magnetic Stimulation (rTMS) in the treatment of panic disorder (PD) with comorbid major depression. J. Affect. Disord 102(1-3), 277280 (2007).

99. Sarkhel S, Sinha VK, Praharaj SK. Adjunctive high-frequency right prefrontal repetitive transcranial magnetic stimulation (rTMS) was not effective in obsessive-compulsive disorder but improved secondary depression. J. Anxiety Disord 24(5), 535-539 (2010).

100. Kim DR, Wang E, McGeehan B, et al. Randomized controlled trial of transcranial magnetic stimulation in pregnant women with major depressive disorder. Brain. Stimul S1935-861X(18), 30307-30303 (2018).

101. Lee SJ, Kim DY, Chun MH, et al. The effect of repetitive transcranial magnetic stimulation on fibromyalgia: a randomized sham-controlled trial with 1-mo follow-up. Am. J. Phys. Med. Rehabil 91(12), 1077-1085 (2012)

102. Fregni F, Marcolin MA, Myczkowski M, et al. Predictors of antidepressant response in clinical trials of transcranial magnetic stimulation. Int. J. Neuropsychopharmacol 9(6), 641-654 (2006).

103. Aguirre I, Carretero B, Ibarra O, et al. Age predicts low-frequency transcranial magnetic stimulation efficacy in major depression. J. Affect. Disord 130(3), 466469 (2011).

104. Brakemeier EL, Luborzewski A, DankerHopfe $\mathrm{H}$, et al. Positive predictors for antidepressive response to prefrontal repetitive transcranial magnetic stimulation (rTMS). J. Psychiatr. Res 41(5), 395-403 (2007).

105. Brakemeier EL, Wilbertz G, Rodax S, et al. Patterns of response to repetitive transcranial magnetic stimulation (rTMS) in major depression: replication study in drug-free patients. J. Affect. Disord 108(12), 59-70 (2008).

106. Zhang T, Zhu J, Xu L, et al. Add-on rTMS for the acute treatment of depressive symptoms is probably more effective in adolescents than in adults: Evidence from real-world clinical practice. Brain Stimul. pii: S1935-861X(18), 30309-30307 (2018).

107. Holtzheimer PE, Russo J, Claypoole $\mathrm{KH}$, et al. Shorter duration of depressive episode may predict response to repetitive transcranial magnetic stimulation. Depress. Anxiety 19(1), 24-30 (2004).

108. Schiffer F, Stinchfield Z, Pascual-Leone
A. Prediction of clinical response to transcranial magnetic stimulation for depression by baseline lateral visualfield stimulation. Neuropsychiatry. Neuropsychol. Behav. Neurol 15(1), 18-27 (2002).

109. Berlim MT, McGirr A, Beaulieu MM, et al. Are neuroticism and extraversion associated with the antidepressant effects of repetitive transcranial magnetic stimulation (rTMS)?. An exploratory 4-week trial. Neurosci. Lett 534(1), 306-310 (2013).

110. Furtado CP, Hoy KE, Maller JJ, et al. Cognitive and volumetric predictors of response to repetitive transcranial magnetic stimulation (rTMS) - a prospective follow-up study. Psychiatry. Res 202(1), 12-19 (2012).

111. Hernandez-Ribas R, Deus J, Pujol J, et al. Identifying brain imaging correlates of clinical response to repetitive transcranial magnetic stimulation (rTMS) in major depression. Brain. Stimul 6(1), 54-61 (2012).

112. Paillere Martinot ML, Martinot JL, Ringuenet $\mathrm{D}$, et al. Baseline brain metabolism in resistant depression and response to transcranial magnetic stimulation. Neuropsychopharmacology 36(13), 2710-2719 (2011).

113. Kito S, Hasegawa T, Koga Y. Cerebral blood flow ratio of the dorsolateral prefrontal cortex to the ventromedial prefrontal cortex as a potential predictor of treatment response to transcranial magnetic stimulation in depression. Brain. Stimul 5(4), 547-553 (2012).

114. Kito S, Hasegawa T, Koga Y. Cerebral blood flow in the ventromedial prefrontal cortex correlates with treatment response to low-frequency right prefrontal repetitive transcranial magnetic stimulation in the treatment of depression. Psychiatry. Clin. Neurosci 66(2), 138-145 (2012).

115. Kito $S$, Hasegawa T, Koga $Y$. Neuroanatomical correlates of therapeutic efficacy of low-frequency right prefrontal transcranial magnetic stimulation in treatment-resistant depression. Psychiatry. Clin. Neurosci 65(2), 175-182 (2011).

116. Vink JJT, Mandija S, Petrov PI, et al. A novel concurrent TMS-fMRI method to reveal propagation patterns of prefrontal magnetic brain stimulation. Hum. Brain. Mapp 39(11), 4580-4592 (2018).

117. Nadeau SE, McCoy KJ, Crucian GP, et al. Cerebral blood flow changes in depressed patients after treatment with repetitive transcranial magnetic stimulation: evidence of individual variability. Neuropsychiatry. Neuropsychol. Behav.
Neurol 15(3), 159-175 (2002).

118. Shinba T, Kariya N, Matsuda S, et al. Increase of frontal cerebral blood volume during transcranial magnetic stimulation in depressionis related to treatment effectiveness: A pilot study with nearinfrared spectroscopy. Psychiatry. Clin. Neurosci 72(8), 602-610 (2018).

119. Khodayari-Rostamabad A, Reilly JP, Hasey GM, et al. Using pre-treatment electroencephalography data to predict response to transcranial magnetic stimulation therapy for major depression. Conf. Proc. IEEE. Eng. Med. Biol. Soc 2011(1), 6418-64121 (2011).

120. Hunter AM, Nghiem TX, Cook IA, et al. Change in Quantitative EEG Theta Cordance as a Potential Predictor of Repetitive Transcranial Magnetic Stimulation Clinical Outcome in Major Depressive Disorder. Clin. EEG. Neurosci 49(5), 306-315 (2018).

121. Narushima K, McCormick LM, Yamada T, et al. Subgenual cingulate theta activity predicts treatment response of repetitive transcranial magnetic stimulation in participants with vascular depression. J. Neuropsychiatry Clin. Neurosci 22(1), 75-84 (2010).

122. Philip NS, Barredo J, van 't Wout-Frank $M$, et al. Network Mechanisms of Clinical Response to Transcranial Magnetic Stimulation in Posttraumatic Stress Disorder and Major Depressive Disorder. Biol-Psychiatry 83(3), 263-272 (2018).

123. Micoulaud-Franchi JA, Richieri R, Cermolacce $\mathrm{M}$, et al. Parieto-temporal alpha EEG band power at baseline as a predictor of antidepressant treatment response with repetitive Transcranial Magnetic Stimulation: a preliminary study. J. Affect. Disord 137(1-3), 156-160 (2012).

124. Oliveira-Maia AJ, Press D, Pascual-Leone A. Modulation of motor cortex excitability predicts antidepressant response to prefrontal cortex repetitive transcranial magnetic stimulation. Brain. Stimul 10(4), 787-794 (2017).

125. Klein E, Kreinin I, Chistyakov A, et al. Therapeutic efficacy of right prefrontal slow repetitive transcranial magnetic stimulation in major depression: a double-blind controlled study. Arch. Gen. Psychiatry 56(4), 315-320 (1999).

126. Menkes DL, Bodnar P, Ballesteros RA, et al. Right frontal lobe slow frequency repetitive transcranial magnetic stimulation (SF r-TMS) is an effective treatment for depression: a case-control pilot study of safety and efficacy. J. Neurol. Neurosurg. Psychiatry 67(1), 113-115 (1999). 
127. Schutter DJ, van Honk J, Laman M, et al. Increased sensitivity for angry faces in depressive disorder following 2 weeks of $2-\mathrm{Hz}$ repetitive transcranial magnetic stimulation to the right parietal cortex. Int. J. Neuropsychopharmacol 3(9), 11551161 (2010).

128. Isenberg K, Downs D, Pierce K, et al. Low frequency rTMS stimulation of the right frontal cortex is as effective as high frequency rTMS stimulation of the left frontal cortex for antidepressant-free, treatment-resistant depressed patients. Ann. Clin. Psychiatry 17(3), 153-159 (2005)

129. Kauffmann CD, Cheema MA, Miller $B E$. Slow right prefrontal transcranial magnetic stimulation as a treatment for medication-resistant depression: a double-blind, placebo-controlled study. Depress. Anxiety 19(1), 59-62 (2004).

130. Rossini D, Lucca A, Magri L, et al. A symptom-specific analysis of the effect of high-frequency left or low-frequency right transcranial magnetic stimulation over the dorsolateral prefrontal cortex in major depression. Neuropsychobiology 62(2), 91-97 (2010)

131. Bares M, Kopecek M, Novak T, et al. Low frequency $(1-\mathrm{Hz})$, right prefrontal repetitive transcranial magnetic stimulation (rTMS) compared with venlafaxine ER in the treatment of resistant depression: a double-blind, single-centre, randomized study. J. Affect. Disord 118(1-3), 94-100 (2009).

132. Berlim MT, Van den Eynde F, Jeff Daskalakis Z. Clinically Meaningful Efficacy and Acceptability of LowFrequency Repetitive Transcranial Magnetic Stimulation (rTMS) for Treating Primary Major Depression: A Meta-Analysis of Randomized, DoubleBlind and Sham-Controlled Trials. Neuropsychopharmacology 38(4), 543 551( 2013).

133. Chen J, Zhou C, Wu B, et al. Left versus right repetitive transcranial magnetic stimulation in treating major depression: A meta-analysis of randomised controlled trials. Psychiatry. Res 210(3), 1260-1264 (2013).

134. Speer AM, Kimbrell TA, Wassermann EM, et al. Opposite effects of high and low frequency rTMS on regional brain activity in depressed patients. Biol. Psychiatry 48(12), 1133-1141 (2000).

135. Loo CK, Sachdev PS, Haindl W, et al. High $(15 \mathrm{~Hz})$ and low $(1 \mathrm{~Hz})$ frequency transcranial magnetic stimulation have different acute effects on regional cerebral blood flow in depressed patients. Psychol. Med 33(6), 997-1006 (2003).

136. Kito S, Fujita K, Koga Y. Regional cerebral blood flow changes after low-frequency transcranial magnetic stimulation of the right dorsolateral prefrontal cortex in treatment-resistant depression. Neuropsychobiology 58(1), 29-36 (2008).

137. Eche J, Mondino M, Haesebaert $F$, et al. Low- vs High-Frequency Repetitive Transcranial Magnetic Stimulation as an Add-On Treatment for Refractory Depression. Front. Psychiatry 3(1), 13 (2012).

138. Fitzgerald PB, Hoy K, Daskalakis ZJ, et al. A randomized trial of the anti-depressant effects of low- and high-frequency transcranial magnetic stimulation in treatment-resistant depression. Depress. Anxiety 26(3), 229-234 (2009).

139. Hoppner J, Schulz M, Irmisch G, et al. Antidepressant efficacy of two different rTMS procedures. High frequency over left versus low frequency over right prefronta cortex compared with sham stimulation. Eur. Arch. Psychiatry Clin. Neurosci 253(2), 103-109 (2003).

140. Richieri R, Boyer L, Padovani R, et al. Equivalent brain SPECT perfusion changes underlying therapeutic efficiency in pharmacoresistant depression using either high-frequency left or lowfrequency right prefrontal rTMS. Prog. Neuropsychopharmacol. Biol. Psychiatry 39(2), 364-370 (2012).

141. Vanneste $S$, Ost J, Langguth $B$, et al. TMS by double-cone coil prefrontal stimulation for medication resistant chronic depression: A case report. Neurocase 20(1), 61-68 (2014).

142. Kavanaugh BC, Aaronson ST, Clarke GN et al. Neurocognitive Effects of Repetitive Transcranial Magnetic Stimulation with a 2-Coil Device in Treatment-Resistant Major Depressive Disorder. J. ECT 494 (2018).

143. Levkovitz $Y$, Sheer A, Harel EV, et al. Differential effects of deep TMS of the prefrontal cortex on apathy and depression. Brain. Stimul 4(4), 266-274 (2011).

144. Isserles M, Rosenberg O, Dannon P, et al Cognitive-emotional reactivation during deep transcranial magnetic stimulation over the prefrontal cortex of depressive patients affects antidepressant outcome. J. Affect. Disord 128(3), 235-242 (2011).

145. Levkovitz Y, Harel EV, Roth Y, et al. Deep transcranial magnetic stimulation over the prefrontal cortex: evaluation of antidepressant and cognitive effects in depressive patients. Brain. Stimul 2(4), 188-200 (2009).

146. Herbsman T, Avery D, Ramsey D, et al. More lateral and anterior prefrontal coil location is associated with better repetitive transcranial magnetic stimulation antidepressant response. Biol. Psychiatry 66(5), 509-515 (2009).

147. Luber BM, Davis S, Bernhardt E, et al. Reprint of "Using neuroimaging to individualize TMS treatment for depression: Toward a new paradigm for imaging-guided intervention". Neuroimage 151(1), 65-71 (2017).

148. Johnson KA, Baig M, Ramsey D, et al. Prefrontal rTMS for treating depression: Location and intensity results from the OPT-TMS multi-site clinical trial. Brain. Stimul 6(2), 108-117 (2013).

149. Nauczyciel C, Hellier P, Morandi X, et al. Assessment of standard coil positioning in transcranial magnetic stimulation in depression. Psychiatry. Res 186(2-3), 232238 (2011)

150. Schonfeldt-Lecuona C, Lefaucheur JP, Cardenas-Morales $L$, et al. The value of neuronavigated rTMS for the treatment of depression. Neurophysiol. Clin 40(1), 37-43 (2010).

151. Fitzgerald PB, Hoy K, McQueen S, et al. A randomized trial of $\mathrm{rTMS}$ targeted with MRI based neuro-navigation in treatment-resistant depression. Neuropsychopharmacology 34(5), 12551262 (2009).

152. Price GW, Lee JW, Garvey CA, et al. The use of background EEG activity to determine stimulus timing as a means of improving rTMS efficacy in the treatment of depression: a controlled comparison with standard techniques. Brain. Stimul 3(3), 140-152 (2010).

153. Ullrich $H$, Kranaster $L$, Sigges $E$, et al. Ultra-High-Frequency Left Prefrontal Transcranial Magnetic Stimulation as Augmentation in Severely III Patients with Depression: A Naturalistic ShamControlled, Double-Blind, Randomized Trial. Neuropsychobiology 66(3), 141-148 (2012).

154. Holtzheimer PE, McDonald WM, Mufti M, et al. Accelerated repetitive transcranial magnetic stimulation for treatmentresistant depression. Depress. Anxiety 27(10), 960-963 (2010).

155. Chistyakov AV, Rubicsek O, Kaplan B, et al. Safety, tolerability and preliminary evidence for antidepressant efficacy of theta-burst transcranial magnetic stimulation in patients with major depression. Int. J. Neuropsychopharmacol 13(3), 387-393 (2010).

156. Garcia-Toro M, Salva J, Daumal J, et al. High $(20-\mathrm{Hz})$ and low $(1-\mathrm{Hz})$ frequency transcranial magnetic stimulation as adjuvant treatment in medicationresistant depression. Psychiatry. Res 146(1), 53-57 (2006).

157. Fitzgerald PB, Hoy KE, Singh A, et 
al. Equivalent beneficial effects of unilateral and bilateral prefrontal cortex transcranial magnetic stimulation in a large randomized trial in treatmentresistant major depression. Int. J. Neuropsychopharmacol 16(9), 1975-1984 (2013).

158. Fitzgerald PB, Hoy KE, Herring SE, et al. A double blind randomized trial of unilateral left and bilateral prefrontal cortex transcranial magnetic stimulation in treatment resistant major depression. J. Affect. Disord 139(2), 193-198 (2012).

159. Blumberger $D M$, Mulsant $B H$, Fitzgerald $\mathrm{PB}$, et al. A randomized double-blind sham-controlled comparison of unilateral and bilateral repetitive transcranial magnetic stimulation for treatmentresistant major depression. World. J. Biol. Psychiatry 13(6), 423-435 (2012).

160. Donse L, Padberg F, Sack AT, et al. Simultaneous rTMS and psychotherapy in major depressive disorder: Clinical outcomes and predictors from a large naturalistic study. Brain. Stimul 11(2), 337 345 (2018).

161. Fitzgerald PB, Hoy K, Gunewardene R, et al. A randomized trial of unilateral and bilateral prefrontal cortex transcranial magnetic stimulation in treatmentresistant major depression. Psychol. Med 41(6), 1187-1196 (2011).

162. Berlim MT, Van den Eynde F, Daskalakis ZJ. A systematic review and meta-analysis on the efficacy and acceptability of bilateral repetitive transcranial magnetic stimulation (rTMS) for treating major depression. Psychol. Med 43(11), 22452254 (2013).

163. Chen JJ, Zhao LB, Liu YY, et al. Comparative efficacy and acceptability of electroconvulsive therapy versus repetitive transcranial magnetic stimulation for major depression: A systematic review and multipletreatments meta-analysis. Behav. Brain. Res 320(1), 30-36 (2017).

164. Magnezi R, Aminov E, Shmuel $D$, et al. Comparison between neurostimulation techniques repetitive transcranial magnetic stimulation vs electroconvulsive therapy for the treatment of resistant depression: patient preference and costeffectiveness. Patient Prefer. Adherence 10(1), 1481-1487 (2016).

165. Nongpiur A, Sinha VK, Praharaj SK, et al. Theta-patterned, frequency-modulated priming stimulation enhances lowfrequency, right prefrontal cortex repetitive transcranial magnetic stimulation (rTMS) in depression: a randomized, sham-controlled study. J. Neuropsychiatry Clin. Neurosci 23(3), 348357 (2011).
166. Fitzgerald PB, Hoy K, McQueen S, et al. Priming stimulation enhances the effectiveness of low-frequency right prefrontal cortex transcranial magnetic stimulation in major depression. J. Clin. Psychopharmacol 28(1), 52-58 (2008).

167. lyer MB, Schleper N, Wassermann EM. Priming stimulation enhances the depressant effect of low-frequency repetitive transcranial magnetic stimulation. J. Neurosci 23(34), 1086710872 (2003).

168. Filipcic I, Milovac Z, Sucic S, et al. Efficacy, Safety and Tolerability of Augmentative rTMS in Treatment of Major Depressive Disorder(MDD): A Prospective Cohort Study in Croatia. Psychiatr. Danub 29(1), 31-38 (2017).

169. Huang ML, Luo BY, Hu JB, et al. Repetitive transcranial magnetic stimulation in combination with citalopram in young patients with first-episode major depressive disorder: a double-blind, randomized, sham-controlled trial. Aust. N. Z. J. Psychiatry 46(3), 257-264 (2012).

170. Wang HN, Wang XX, Zhang RG, et al. Clustered repetitive transcranial magnetic stimulation for the prevention of depressive relapse/recurrence: a randomized controlled trial. Transl. Psychiatry 7(12), 1292 (2017).

171. Russo GB, Tirrell E, Busch A, et al. Behavioral activation therapy during transcranial magnetic stimulation for major depressive disorder. J. Affect. Disord 236(1), 101-104 (2018)

172. Grisaru N, Chudakov B, Yaroslavsky Y, et al. Transcranial magnetic stimulation in mania: a controlled study. Am. J. Psychiatry 155(11), 1608-1610 (1998).

173. Kaptsan A, Yaroslavsky Y, Applebaum J, et al. Right prefrontal TMS versus sham treatment of mania: a controlled study. Bipolar. Disord 5(1), 36-39 (2003).

174. Michael N, Erfurth A. Treatment of bipolar mania with right prefrontal rapid transcranial magnetic stimulation. J. Affect Disord 78(3), 253-257 (2004).

175. Saba G, Rocamora JF, Kalalou K, et al. Repetitive transcranial magnetic stimulation as an add-on therapy in the treatment of mania: a case series of eight patients. Psychiatry. Res 128(2), 199-202 (2004).

176. Praharaj SK, Ram D, Arora M. Efficacy of high frequency (rapid) suprathreshold repetitive transcranial magnetic stimulation of right prefrontal cortex in bipolar mania: a randomized sham controlled study. J. Affect. Disord 117(3), 146-150 (2009).

177. Xia G, Gajwani P, Muzina DJ, et al. Treatment-emergent mania in unipolar and bipolar depression: focus on repetitive transcranial magnetic stimulation. Int. J. Neuropsychopharmacol 11(1), 119-130 (2008).

178. Grisaru N, Amir M, Cohen H, et al. Effect of transcranial magnetic stimulation in posttraumatic stress disorder: a preliminary study. Biol. Psychiatry 44(1), 52-55 (1998).

179. Watts BV, Landon B, Groft A, et al. A sham controlled study of repetitive transcranial magnetic stimulation for posttraumatic stress disorder. Brain. Stimul 5(1), 38-43 (2012).

180. Nam DH, Pae CU, Chae JH. Low-frequency, Repetitive Transcranial Magnetic Stimulation for the Treatment of Patients with Posttraumatic Stress Disorder: a Double-blind, Sham-controlled Study. Clin. Psychopharmacol. Neurosci 11(2), 96-102 (2013).

181. Cohen H, Kaplan Z, Kotler M, et al. Repetitive transcranial magnetic stimulation of the right dorsolateral prefrontal cortex in posttraumatic stress disorder: a double-blind, placebocontrolled study. Am. J. Psychiatry 161(3), 515-524 (2004).

182. Boggio PS, Rocha M, Oliveira MO, et al. Noninvasive brain stimulation with highfrequency and low-intensity repetitive transcranial magnetic stimulation treatment for posttraumatic stress disorder. J. Clin. Psychiatry 71 (8), 992-999 (2010).

183. Rosenberg PB, Mehndiratta RB, Mehndiratta YP, et al. Repetitive transcranial magnetic stimulation treatment of comorbid posttraumatic stress disorder and major depression. J. Neuropsychiatry Clin. Neurosci 14(3), 270276 (2002)

184. Rossi S, Cappa SF, Ulivelli M, et al. rTMS for PTSD: induced merciful oblivion or elimination of abnormal hypermnesia? Behav. Neurol 17(3-4), 195-199 (2006).

185. Martin JL, Barbanoj MJ, Perez V, et al. Transcranial magnetic stimulation for the treatment of obsessive-compulsive disorder. Cochrane Database Syst. Rev 2003(3), CD003387 (2003).

186. Berlim MT, Neufeld NH, Van den Eynde F. Repetitive transcranial magnetic stimulation (rTMS) for obsessivecompulsive disorder (OCD): an exploratory meta-analysis of randomized and sham-controlled trials. J. Psychiatr. Res 47(8), 999-1006 (2013).

187. Cocchi L, Zalesky A, Nott Z, et al. Transcranial magnetic stimulation in obsessive-compulsive disorder: A focus on network mechanisms and state dependence. Neuroimage. Clin 19(1), 661674 (2018). 
188. Olatunji BO, Ferreira-Garcia R, Caseras $\mathrm{X}$, et al. Predicting response to cognitive behavioral therapy in contaminationbased obsessive-compulsive disorder from functional magnetic resonance imaging. Psychol. Med 44(1), 2125-2137 (2014).

189. Le K, Liu L, Sun M, et al. Transcranial magnetic stimulation at 1 Hertz improves clinical symptoms in children with Tourette syndrome for at least 6 months. J. Clin. Neurosci 20(2), 257-262 (2013).

190. Kwon HJ, Lim WS, Lim MH, et al. 1-Hz low frequency repetitive transcranial magnetic stimulation in children with Tourette's syndrome. Neurosci. Lett 492(1), 1-4 (2011).

191. Garcin B, Roze E, Mesrati F, et al. Transcranial magnetic stimulation as an efficient treatment for psychogenic movement disorders. J. Neurol. Neurosurg. Psychiatry 84(9), 1043-1046 (2013).

192. Hoppner J, Broese T, Wendler L, et al. Repetitive transcranial magnetic stimulation (rTMS) for treatment of alcohol dependence. World. J. Biol. Psychiatry 12(1), 57-62 (2011).

193. Eichhammer $P$, Johann $M$, Kharraz $A$, et al. High-frequency repetitive transcranial magnetic stimulation decreases cigarette smoking. J. Clin. Psychiatry 64(8), 951-953 (2003).

194. Li X, Hartwell KJ, Owens M, et al. Repetitive Transcranial Magnetic Stimulation of the Dorsolateral Prefrontal Cortex Reduces Nicotine Cue Craving. Biol. Psychiatry 73(8), 714-720 (2013).
195. Wing VC, Bacher I, Wu BS, et al. High frequency repetitive transcranial magnetic stimulation reduces tobacco craving in schizophrenia. Schizophr. Res 139(1-3), 264-266 (2012).

196. Prikryl R, Ustohal L, Kucerova HP, et al. Repetitive transcranial magnetic stimulation reduces cigarette consumption in schizophrenia patients. Prog. Neuropsychopharmacol. Biol. Psychiatry 49(1), 30-35 (2014).

197. Erhardt A, Sillaber I, Welt T, et al. Repetitive transcranial magnetic stimulation increases the release of dopamine in the nucleus accumbens shell of morphine-sensitized rats during abstinence. Neuropsychopharmacology 29(11), 2074-2080 (2004). 